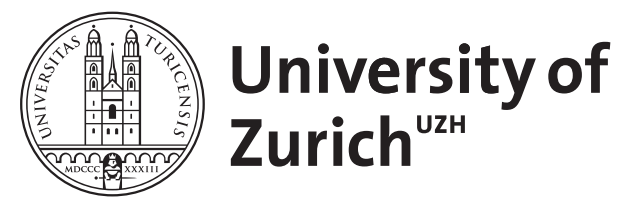

\title{
Notch in Head and Neck Cancer
}

\author{
Porcheri, Cristina ; Mitsiadis, Thimios A
}

\begin{abstract}
Head and neck cancer is a group of neoplastic diseases affecting the facial, oral, and neck region. It is one of the most common cancers worldwide with an aggressive, invasive evolution. Due to the heterogeneity of the tissues affected, it is particularly challenging to study the molecular mechanisms at the basis of these tumors, and to date we are still lacking accurate targets for prevention and therapy. The Notch signaling is involved in a variety of tumorigenic mechanisms, such as regulation of the tumor microenvironment, aberrant intercellular communication, and altered metabolism. Here, we provide an up-to-date review of the role of Notch in head and neck cancer and draw parallels with other types of solid tumors where the Notch pathway plays a crucial role in emergence, maintenance, and progression of the disease. We therefore give a perspective view on the importance of the pathway in neoplastic development in order to define future lines of research and novel therapeutic approaches.
\end{abstract}

DOI: https://doi.org/10.1007/978-3-030-55031-8_7

Posted at the Zurich Open Repository and Archive, University of Zurich

ZORA URL: https://doi.org/10.5167/uzh-197111

Book Section

Accepted Version

Originally published at:

Porcheri, Cristina; Mitsiadis, Thimios A (2021). Notch in Head and Neck Cancer. In: Reichrath, Jörg; Reichrath, Sandra. Notch Signaling in Embryology and Cancer. Cham: Springer, 81-103.

DOI: https://doi.org/10.1007/978-3-030-55031-8_7 
Part of the Advances in Experimental Medicine and Biology "Notch Signaling in Embryology and Cancer" book series

\title{
Notch in Head and Neck Cancer
}

\author{
Cristina Porcheri*1 and Thimios A. Mitsiadis ${ }^{1}$ \\ ${ }^{1}$ Institute of Oral Biology, Orofacial Development and Regeneration, University of Zurich \\ Plattenstrasse 11 \\ *cristina.porcheri@zzm.uzh.ch
}

\begin{abstract}
Head and neck cancer is a group of neoplastic diseases affecting the facial, oral and neck region. It is one of the most common cancers worldwide with an aggressive, invasive evolution in the late stages of malignancy. Due to the heterogeneity of the tissues affected, it is particularly challenging to study the molecular mechanisms at the basis of these tumors, and to date we are still lacking accurate targets for prevention and therapy. Notch signaling is involved in a variety of tumorigenic mechanisms, such as regulation of the tumor microenvironment, cell-to-cell communication and metabolic homeostasis. Here, we provide an up-to-date review of the role of Notch in head and neck cancer and draw parallels with other types of solid tumors where the Notch pathway plays a crucial role in emergence, maintenance and progression of the disease. We therefore give a perspective view on the importance of the pathway in neoplastic development in order to define future lines of research and novel therapeutic approaches.
\end{abstract}

\section{Keywords}

Notch pathway; Oral Epithelium; Oral Mucosa; Epithelial Notch; Oral cancer; Carcinoma; Squamous Cell Carcinoma; Cell-to-Cell Interaction; Intercellular Communication; 


\section{List of abbreviations}

\begin{tabular}{|c|c|}
\hline ADAM & A Disintegrin And Metalloproteinase \\
\hline AKT & Protein Kinase B \\
\hline APC & Adenomatous polyposis coli \\
\hline $\mathrm{CAF}$ & Cancer-associated fibroblast \\
\hline CCL & Chemokine (C-C motif) ligand \\
\hline CCND1 & Cyclin D1 \\
\hline $\mathrm{cK}$ & Cytokeratin \\
\hline $\mathrm{COX} 2$ & Cyclooxygenase- 2 \\
\hline $\mathrm{CSC}$ & Cancer stem cell \\
\hline CXCL & CXC chemokine ligand \\
\hline CXCR & CXC chemokine receptor \\
\hline $\mathrm{CRC}$ & Colorectal cancer \\
\hline $\mathrm{DC}$ & Dendritic cells \\
\hline DLL & Delta-like \\
\hline $\mathrm{EGF}(\mathrm{R})$ & Epidermal growth factor (receptor) \\
\hline EMT & Epithelial-to-mesenchymal transition \\
\hline FBXW7 & F-box and WD repeat domain containing 7 \\
\hline GSI DAPT & Gamma-secretase inhibitors \\
\hline Hes & Hairy and enhancer of split-1 \\
\hline Hey & Hairy/enhancer-of-split related with YRPW motif protein 1 \\
\hline Hif1 & Hypoxia-inducible factor 1 \\
\hline HNSCC & Head and neck squamous cell carcinoma \\
\hline HPV & human papillomavirus \\
\hline IL & Interleukin \\
\hline ILC & Innate lymphoid cell \\
\hline LAC & Lung adenocarcinoma \\
\hline LNR & Cysteine-rich Lin-12/Notch Repeats \\
\hline LPS & Lipopolysaccharide \\
\hline $\mathrm{mAb}$ & Monoclonal antibody \\
\hline MALM & Mastermind-like \\
\hline MET & Mesenchymal-to-epithelial-transition \\
\hline
\end{tabular}


MMP Matrix metalloproteinase

MMTV Mouse mammary tumor virus

NCR Natural cytotoxicity receptor

NF- $\kappa$ B Nuclear factor kappa-light-chain-enhancer of activated B cells

NICD Notch intracellular domain

NK Natural killer cells

NLS Nuclear localizing sequence

Oct4 Octamer-binding transcription factor 4

OSCC Oral Squamous Cell Carcinoma

PTEN Phosphatase and tensin homolog

PI3K Phosphatidylinositol 3-kinase

$\mathrm{RBPj} \quad$ Recombination signal binding protein for immunoglobulin kappa $\mathbf{J}$ region

SCC squamous cell carcinoma

Shh Sonic hedgehog

Sox 2 Sex determining region Y-box 2

STAT Signal transducer and activator of transcription

TAM Tumor associated macrophages

T-ALL T cell acute lymphoblastic leukemia

TCF T-cell factor

TGF- $\beta \quad$ Transforming growth factor- $\beta$

TLR Toll-like receptor

TNF- $\alpha \quad$ Tumor necrosis factor alpha

VEGF(R) Vascular endothelial growth factor (receptor)

$\alpha$-SMA $\quad \alpha$-smooth muscle actin 


\section{Introduction}

Head and neck cancers (HNSCCs) represent a group of neoplastic diseases affecting different tissues and organs in the head and neck anatomical region. An estimated 5.5 million people are affected by HNSCCs with a poor prognosis of survival (379.000 deaths in 2015). More than 90\% of HNSCCs are carcinomas that mainly emerge from the epithelial wall of the oral cavity, although several other tissues, such as the nasal cavity, pharynx, larynx and salivary glands, can also be affected [1-4]. Carcinogenesis is often triggered by chronic exposure to tobacco or alcohol, but it might also be associated with viral infections, commonly the human papillomavirus (HPV) infection [5-7]. Alcohol dissolves the lipid barrier in the external part of the epithelium and is metabolized into acetaldehyde, which in turn reacts with DNA molecules to induce damage (including adducts, single- and double-strand breaks, and point mutations) [5, 8]. Similarly, tobacco-derived carcinogens (such as benzopyrenes, aromatic amines, and nitrosamines) covalently bind DNA, inducing gene mutations [9]. Finally, chemical exposure reduces the local immune-surveillance, and local inflammation increases susceptibility to cancer development $[5,7]$. Thus, chemically-promoted DNA damage often results in an aberrant repair process, consequently causing uncontrolled proliferation and dysplasia of the epithelial layers [8].

Conversely, infections with HPV require the presence of a preexisting wound, which allows the virus to reach the basal cell layer and integrate its dsDNA into the DNA of the host cell, ultimately exploiting the proliferative machinery of the epithelial tissue $[6,10]$. Abrasion through mastication is a common cause of wound occurrence, and therefore tongue and oral mucosa are the most common sites of cancer development [11, 12].

Less common neoplasms of the head and neck region include odontogenic tumors and tumors of the salivary glands. Salivary glands tumors represent $6 \%$ of all HNSCCs and mainly occur in the parotid gland. A substantial risk factor for the development of a salivary gland tumor is 
exposure to ionizing radiation, which is typically used in radiotherapy. Odontogenic tumors are a heterogeneous group arising specifically in the jaw and are classified based on their peculiar ability to generate aberrant interconnection between ectomesenchyme and epithelium. Malignant odontogenic tumors are quite rare, however their benign counterparts are able to infiltrate surrounding structures, alter their architecture and function, and ultimately evolve into malignancy. Of the most common types of odontogenic tumors, the ameloblastoma and intra-osseous carcinoma have epithelial origin and involve progression from altered odontogenic epithelium or an odontogenic cyst [13].

\section{Histology of craniofacial epithelium}

Epithelium lining the respiratory and digestive tract are often formed by squamous epithelium, of the simple or stratified type. Simple squamous cells line the air sacs of the lungs and heart, blood and lymphatic vessels, and are characterized by a single layer of epithelial cells resting on the basal lamina. Stratified squamous cell epithelium characterizes the epithelium of the oral and nasal cavity, the esophagus and also skin and vaginal walls. In contrast to the simple version of squamous epithelium, the stratified epithelium is composed of several overlapping layers of flattened cells, of which the first layer is in direct contact with the basement membrane. Cells are bound together by tight junctions with very limited or absent intercellular space. These structures allow resistance to constant abrasion and are normally found in areas where the physical barrier of the body meets with the external environment. The continuous exposure to sheering forces induces a constant elimination of older cells from the external layers. As a result, stem and progenitor cells located in the deep basal layers undergo a proliferation stage and progress further in their maturation process, replenishing the outer layers of the stratified epithelium. Therefore, this type of epithelium faces a fast turnover, with 
cycles of stem cell activation, increased proliferation, and differentiation occurring in a finely coordinated manner.

In the head and neck region, the protective layers of a stratified squamous cell epithelium are the major protective structure of the tongue, oral mucosa, internal portion of the lips, larynx, and pharynx (Figure 1). Similarly, within specialized skin such as the palm of the hand or the sole of the foot, the oral mucosa is additionally protected by a keratinized external layer. Cytokeratins (cK) are fibrous structural proteins abundant in epithelial cells, and the expression of specific keratins within a tissue determines both the type of cell and the function of the tissue. High levels of keratins increase the endurance of epithelium to mechanical stresses, and at the same time preserve hydration of its deeper layers. The basal epithelial cell layer, called stratum basale, contains slow-cycling stem cells that are anchored to the basement membrane. The larger portion of the stratified epithelium is composed by several layers of proliferating progenitors that are generated from stem cells via asymmetric cell divisions and passively displaced toward the surface. When proliferative progenitors differentiate further they acquire an elongated shape, leading to a tightening of the intercellular space by expression of modified desmosomes in the stratum granulosum. The most external layer of the squamous stratified epithelium is composed of maturing cells that produce and accumulate large amounts of protein aggregates containing keratin filaments. The large amount of aggregates promotes the collapsing and flattening of the corneocytes, while the synthesis of other proteins (involucrin, trichohyalin, and other small proline-rich proteins) continues. Proteins integrate into the plasma membrane, where they physically interact with membrane lipids (ceramides and cholesterol) to provide a waterproof barrier. Once desquamation is induced by abrasion, desmosomes are degraded, cells detach and are thus released from the epithelial structure. 
More specialized epithelia characterize other head and neck regions, such as the ciliated pseudostratified columnar epithelium of the nasal cavity, trachea, and upper respiratory tract. Here, a single layer of ciliated columnar epithelial cells is positioned in direct contact with the basal lamina (Figure 1). They possess cilia, projections extruding from the cell membrane, which help to trap particles brought in through respiration. Finally, the secretory function of the salivary glands is supported by cuboidal and columnar epithelium, which are differentially distributed within acini and ducti, and are functionally important for the distinct levels of permeability of these structures to ions and water (Figure 1) [14].

Epithelial turnover varies greatly depending on the region analyzed (50 to 75 days in the skin, 4 to 14 days in the gut, 40 to 55 days in gingiva, and 25 days in the oral mucosa of the cheek) and correlates with epithelial maturation. Cancer treatment severely affects the dynamics of epithelium maturation and regeneration, as it interferes with mitosis regulation. Following chemotherapy for oral cancers, patients often develop ulcers, experience painful conditions, and have difficulty in maintaining oral hygiene, eating, and drinking.

\section{Epithelial Notch from embryo to cancer}

Mammalian epithelial tissues derive from all three embryonic germ layers and form different anatomical structures (i.e., epidermis derives from the ectoderm, inner epithelial wall from mesoderm, and gut epithelium derives from the endoderm). The epithelium of the head and neck region has a heterogeneous nature from the beginning of its development. The oral mucosa is subdivided into epithelial walls composing palate, floor of the mouth, inner lips and gingiva, all structures that are derived from the ectoderm. Conversely, the epithelium of the tongue is derived from endoderm and mesoderm $[15,16]$. Embryonic epithelial structures often constitute organ primordia, and aid in shaping future functional units as a result of cell-to-cell interactions that coordinate specific molecular program activation, mechanical stimuli, and 
induction of maturation. During early embryonic stages (gestational week four in humans) neural crest cells migrate to the first and second pharyngeal arches to instruct the local epithelial structure in forming bone and cartilage of the face and neck, but also pigment and cranial nerves. Once within the pharyngeal arch, neural crest cells surround a specific portion of the epithelium and give rise to odontoblasts, small bones of the middle ear and thymic cells [17]. The molecular mechanisms involved in the specification of craniofacial epithelium are largely unknown, but the essential role of cell-to-cell communication appears to play a major role in orchestrating maturation and dynamics of epithelial organs. In regards to intercellular communication, the Notch pathway plays an essential role in both inside-out and outside-in molecular activation [18]. In mammals, four Notch receptors interact with specific ligands (three of the delta-like type: D111, D113; Dl14 and two of the jagged type: Jagged1, Jagged2) to regulate fate determination, survival, proliferation and regulation of transcription (Figure 2). Upon receptor interaction with the ligand, the intracellular portion of Notch is cleaved and transmigrates into the nucleus, where it recruits a transcription complex responsible for regulating the expression of specific target genes (among others of the Hes and Hey family: Hes1-7 and Hey1, Hey2, HeyL).

Specifically, the Notch target family of Hes genes is thought to be involved in the definition of a variety of head and neck structures, as mutations in this gene produce defects in frontal bone agenesis, cranial base formation, proper size definition of lower and upper maxilla and are involved in palate cleft. These malformations are associated with an uncontrolled migration and directional role of the neural crest stem cells, which might utilize Hes1 as a regulator of local morphogenesis. Similarly, Hey1 was reported to be expressed in the branchial arches from early to late facial development, where a clear expression is confined to the epithelium of the nasal pit [19]. 
During embryonic development, several epithelial structures express Notch3 and Notch1 receptors, together with the ligands Jagged1 and 2, and are involved in craniofacial morphogenesis [20]. Alagille syndrome patients have mutations in the gene coding for the Jagged1 ligand, resulting in facial hypoplasia and craniosynostosis. Depletion of the Jagged2 ligand results in altered tooth morphogenesis, mainly due to aberrant ameloblast differentiation and poor enamel deposition. Additionally, mutations of the Jagged 2 gene result in the abnormal fusion between palatal processes and the tongue, causing cleft palate. The Notch pathway has a specific role in the regulation of tongue morphogenesis, where the crosstalk between Notch activity and the canonical Wnt signaling pathway directs the boundary formation between epithelium and mesenchyme, inducing the formation of the lamina propria during tongue organogenesis [20].

Due to the involvement of Notch signaling in epithelial tissue definition and its role in balancing stem cell maintenance and differentiation, its activation is common to a variety of embryonic epithelial structures [21]. In particular, the tongue epithelium shares strong similarities with the keratinized epithelium of the skin. From E8.5 in the mouse embryos, ectodermal cells activate the expression of $\mathrm{cK} 5$ and $\mathrm{cK} 14$ as differentiation markers of keratinocyte fate acquisition [22, 23]. Ectodermal cells at specific locations become columnar (epidermal placode) and interacting mesenchymal cells start to secrete extra-cellular matrix molecules that will provide an initial lamina upon which the epithelial stratification is built [24-28]. Ectodermal progenitors that acquire keratinocyte fate start to express the differentiation marker p63 first, followed by keratin 14 . Notch signaling is activated upstream of these markers, as blockage of the Notch signaling leads to a failure of keratinocyte differentiation in the mouse embryos $[29,30]$.

Various events occurring during development are recapitulated during tumorigenesis, such as the establishment of a supportive niche for undifferentiated cells, epithelial-to-mesenchymal 
transition and change of balance between stem cell maintenance and differentiation (Figure 3). The Notch pathway is involved in the regulation of common embryonic and oncogenic processes, and it is therefore not surprising that aberrant expression of Notch receptors and ligands are hallmarks of several solid tumors, including head and neck tumors [31]. Epithelial Notch has been specifically linked to the maintenance of cancer stem cells, the increase in invasion capabilities promoting epithelial-to mesenchymal transition (EMT) and the constitution of a supportive tumor microenvironment (TME) (Figure 3).

\section{Notch in cancer stem cells}

Cells with stem cell characteristics have been identified in a variety of cancers, including colon, pancreatic, lung and prostate carcinomas. Due to their low rate of proliferation, undifferentiated cells inside the tumor can escape chemotherapy and radiotherapy treatments and activate primordial programs for tissue homeostasis. Notch signaling is one of the major pathways involved in preserving undifferentiation of stem cells in both healthy and cancerogenic conditions [21], and has been specifically linked to cancer stem cell (CSC) self-renewal [3234]. The Notch pathway increases stem cell survival in a variety of cancers (such as glioma and medullobloastoma [35]) and its activity results in induced de-differentiation of committed cells into more undifferentiated progenitors, as well as expansion of the stem cell pool by proliferation (i.e. mammary stem cells and mammospheres $[36,37])$. A similar role of Notch is preserved in non-epithelial tumors, such as acute myeloid leukemia, where blocking the Notch pathway affects the survival of CD34+/CD38- undifferentiated populations [38].

Epithelial Notch operates as a stem cell keeper in a variety of tissues, with a few notable exceptions. In the head-neck region and specifically in the oral epithelium, stem cells located in the basal layer express the Notch1 receptor, although genetic depletion of Notch1 was 
reported to have limited effects on the maturation of normal mucosa that displays unaltered morphology and expression of differentiated keratinocytes markers such as cK13 and cK15 $[39,40]$. In oral squamous cell carcinomas, the level of Notch expression correlates with tumor development and severity of dysplasia. In-vitro assays based on HNSCC-derived spheres showed high expression of Notch1 and a direct role for Notch1 in regulating their self-renewal. Overexpression of cleaved Notch induces the expression of classical stem cells markers, such as Oct4, Sox2 and CD44, while knock-out of Notch1 inhibits tumor formation and increases sensitivity to chemotherapy [41].

As previously noted, the Notch signaling pathway has diverse, context-dependent functions. For example, in the adult gut, Notch preserves proliferation and undifferentiation via interaction with D111 and Dll4 ligands [42]. Notch1 upregulation results in maintenance of an undifferentiated state in colon cancer, mainly by interaction with Jagged1 and activation of Hes1 [43-47]. In epidermal tumors, Notch works as a tumor-suppressor, promoting differentiation of uncommitted progenitors in the hair follicle, sebaceous glands and interfollicular epidermis [48, 49]. During the development of embryonic epidermis, Notch activity regulates the expression of p63, an important transcription factor involved in stem cell maintenance, and its upregulation in the basal layer prompts progression of differentiation [29, 50-52]. Consistently, Notch deletion induces the development of spontaneous squamous cell carcinoma in the skin, probably via the Jagged1 ligand $[52,53]$.

Due to the central role of Notch in preserving the more resistant core of cancer stem cells inside the tumor, the Notch signaling pathway represents a major therapeutic target. Radiotherapy treatments were shown to increase the activity of the Notch pathway, particularly in breast cancer and glioma stem cells. The radioprotective role of Notch might be linked with the 
Notch-dependent regulation of the AKT/PI3K pathway, which is specifically activated by the subpopulation of undifferentiated cells sustaining tumor survival $[54,55]$.

\section{Notch in Epithelial to Mesenchymal Transition}

It is now widely accepted that epithelial cells can acquire a mesenchymal phenotype by the process of epithelial to mesenchymal transition (EMT). Upon tissue-reorganization stimuli, such as wound healing, embryonic development and cancerogenic conditions, epithelial cells can undergo a remarkable change in morphology, modifying their genetic expression panel to acquire mesenchymal features. Specifically, they downregulate molecules involved in cell-tocell junctions, such as E-cadherin and $\gamma$-catenin, destabilizing the epithelial structure and promoting cell migration [56-58]. An internal reorganization of the actin cytoskeleton together with the upregulation of mesenchymal markers (such as vimentin, fibronectin, $\alpha$-smooth muscle actin, fibrillar collagen type I and type III and fibroblast-specific protein-1) complete their change of fate [56-58]. Once the cell-to-cell interactions are disassembled, cells in

transition start to produce and secrete matrix metalloproteases (MMPs) like MMP-2, MMP3 and MMP9, increasing motility and invasion capabilities [58, 59]. The Notch pathway has been found to be a major regulator in EMT, by regulating E-cadherin regulation of expression, the TGF $\beta$ pathway and growth factor signaling. Repressors of E-cadherin genes (such as Snail and Slug) bind to the E-cadherin promoter to inhibit gene transcription [60]. Notch directly regulates Snail and Slug, inducing their upregulation in epithelial cells and consequently downregulating E-cadherin expression, a crucial step in the early phase of EMT [61, 62]. Additionally, Notch could control the expression of a hypoxic environment that would stabilize the Snail-1 protein [63].

EMT is an essential event during wound healing and embryonic development and is Notchdependent. For instance, during cardiac development, the Notch signaling pathway is expressed 
in endocardium and cardiac valve maturation and both structures depend on EMT for completion. Similarly, embryos carrying Notch mutations or cardiac explants exposed to the Notch inhibitor DAPT experience impaired EMT, which results in an aberrant cardiac valve formation [61].

In tumorigenic processes, downregulation of E-cadherin with a simultaneous increase of Snail expression is a hallmark of carcinomas [64]. Activation of the EMT program can be triggered at the pre-malignant state of carcinoma, although their prognostic relevance in predicting the formation of new metastases remains to be elucidated $[65,66]$. Interestingly, human samples and disease models display an incomplete form of EMT with epithelial and mesenchymal transcripts coexpressed in tumor cells $[67,68]$. This partial activation of EMT allows tumor cells to convert back to an epithelial fate via a mesenchymal-to-epithelial-transition (MET) when needed, increasing the level of plasticity of the invasive cancer (Figure 3). Cells from the primary tumor can therefore utilize this great adaptability to establish metastases in distant tissues, increasing their heterogeneity and making their identification via transcriptional signature more challenging [69]. How EMT and MET contribute mechanistically to the spreading of the tumor remains to be understood. Alterations to the surrounding microenvironment may help EMT establishment. Hypoxic conditions often present in poorly vascularized portions of carcinoma can contribute to the establishment of an EMT program. Hif-1, a major hypoxia-activator, indirectly represses the expression of epithelial key factors (such as E-cadherin) and thus promotes a mesenchymal differentiation [70, 71].

EMT is particularly important in conferring drug resistance (specifically to taxol, vincristine and oxaliplatin treatment $[72-75])$, and may be a useful therapeutic target to prevent the acquisition of an invasive phenotype and the development of metastases. Therefore, understanding the precise mechanism that governs EMT is an essential step for future cancer 
therapy, and Notch-dependent regulation of EMT offers a promising target for the molecular dissection of this process in human malignancies.

\section{Notch in tumor microenvironment}

A specialized tumor microenvironment (TME) sustains, nourishes and protects tumor cells, which in turn can thrive supported by novel angiogenesis, a cooperative immune system, a modified extracellular matrix. Solid tumors strongly rely on the intercellular communications with the surrounding environment for their maintenance. Cell-to-cell interactions become central in the regulation and generation of a cancerogenic milieu, and the Notch molecular pathway has been implicated in the regulation of various factors shaping the TME [76]. As previously described, the expression of cadherins and integrins might directly depend on Notch regulation, being direct targets of the activated pathway. In parallel, Notch might also coordinate the activity of a subpopulation of resident cells (such as immune and endothelial cells) in the formation of a cancerous-prone environment.

\section{Notch in tumor macrophages}

TME is characterized by very specific immune infiltrates that can be exploited by the cancer itself for local release of tumorigenic factors. A specific subpopulation of bone marrow-derived monocytes give rise to tumor associated macrophages (TAMs) that invade the aberrant tissue. Using the CCL2-CCR2- chemokine pathway, TAMs are recruited by the growing tumor mass whose constant release of trophic cytokines enhances angiogenesis and suppresses antitumoral T-cell response [77]. TAMs have been identified in a variety of solid tumors of epithelial origin, such as breast cancer, bladder, ovarian [78-80] and head and neck cancers [81-83]. Macrophages are generally classified in M1 or M2 subgroups (Figure 3). M1 macrophages are characterized by a pro-inflammatory phenotype, in that they release anti-tumoral cytokines 
such as TNF $\alpha$, IL1b, IL-6 and CXC10, and their polarization is induced upon LPS or TNF $\alpha$ exposure. Tumor cells instead induce the acquisition of the M2 phenotype, characterized by the production and secretion of high levels of IL10, IL4, TGF $\beta$, VEGF and matrix metalloproteases to promote tumor survival and invasiveness. In addition to the regulation of the inflammatory milieu, TAMs might also be involved in controlling the EMT process, as suggested by in-vitro models [84]. Both subtypes of macrophages express the CD68 markers, while expression of M2 macrophages inside the tumor is specified by the expression of CD163. In oral and oropharyngeal carcinoma, high infiltrates positive for CD68 are a hallmark of the cancerogenic condition already present during the early stages of OSCC [85]. A correlative paradigm between poor survival rate in OSCC and high CD163 expression appears to be present in human samples where the TAM population localizes inside the tumor nest rather than in the tumor stroma $[86,87]$. Although the role of the M2 subpopulation seems to be the most relevant in shaping the tumor microenvironment, we cannot exclude a partial role of the M1 macrophages, as sub-distribution of the two populations might be relevant to understanding their mode of action. Additionally, a specific marker for M1 macrophages is still to be found, and their presence in a confined portion of the tumorigenic area cannot be excluded.

The Notch pathway has been largely associated with the induction of differentiation in both central and peripheral lymphoid organs, contributing to the development of the T and B-cell line of lymphocytes. Notch might also be involved in the process of monocytic differentiation starting very early in the progenitor definition and fate acquisition. Gene expression barcoding revealed that Notch controls a myelomonocytic-specific gene signature via inhibition of transcription mediated by Hes1 [88]. Additionally, macrophages and dendritic cells constitutively express members of the Notch family whose expression are regulated by the tolllike receptor (TLR) [89]. TLR upregulates the expression of receptors and Jagged1, D111, D114 
ligands directly promote Notch-pathway activation. During inflammation, cytokines like TNF and IL1b can induce the expression of Notch1, Notch4 and Jagged2 [90]. As both inflammatory cytokines and TLR activate the NFkB pathway, it has been postulated that this pathway functions as a molecular bridge in many systems, including cancer [91]. In contrast with a proinflammatory fate acquisition driven by Notch activation, RBPJ depletion in TAMs blocks their differentiation and induces a previously inhibited cytotoxic T-cell response [92]. Therefore, it remains to be clarified whether blockage of Notch signalling involved in the proinflammatory induction can dampen the immune activation unfavorable for tumor growth. In epithelial cancers, Notch1 and Notch2 signaling through Jagged1 induces a TAM-antiinflammatory phenotype [93]. Interestingly, in head and neck squamous cell carcinoma, high levels of the Notch1 receptor are correlated with a high infiltration of CD163 ${ }^{+}$TAMs $[92,94$, 95].

Due to their supportive role in tumor growth and evolution, TAMs are under the spotlight as emerging therapeutic targets. Blockage of the $\mathrm{CCl} 2 / \mathrm{CCR} 2$ interaction has been shown to be beneficial in human pancreatic ductal adenocarcinoma as it interferes with TAM recruitment [96]. Maturation of monocytes into M2 macrophages depends on IL6, which acts in synergy with other factors (such as COX2-dependent prostaglandin production and STAT3 activation). Current clinical trials are therefore focusing on inhibition of IL-6 and COX2 enzymes with promises to contrast lung and ovarian cancer progression [97, 98].

\section{Notch in tumor angiogenesis}

The tumor vasculature is an essential asset providing trophic support in solid tumor masses. Cancer cells secrete endothelial growth factors that sustain sprouting, migration and rearrangement of vessels, in order to regulate the income of oxygen and nutrients enabling tumor growth. Notch signaling is a major regulator of physiological and aberrant angiogenesis, 
mainly through the Jagged1 or Dll4 ligands [99]. Vasculature dynamics depend on the coordinated activity of tip and stalk cells: high activation of Notch1 induces acquisition of the stalk phenotype, while low Notch activity is associated with tip-cell fate determination [100]. The difference in activity is directly associated with the type of ligand expressed on the surface of the different cell types, with tip cells expressing high levels of Dll4 and stalk cells expressing low levels of Dl14 and high levels of Jagged1 [101]. This in turns regulates the expression of the VEGF receptor and cell metabolism to drive directional sprouting and new vasculature formation [100].

Tumors modify this balance to create the most suitable environment for their own growth, with high levels of Jagged1 inducing an increase in tumor vasculature and Jagged1 downregulation leading to decreased angiogenesis [102]. Metastatic tumors use the newly generated vasculature to enable spreading of mobilized cancer cells and may directly regulate endothelial cell quiescence [103]. Breast cancer cells, otherwise kept quiescent, proliferate in the presence of newly generated microvasculature derived from lung, brain and bone marrow tumors, suggesting that a stable vasculature contributes to a dormant niche, while sprouting, activated endothelial cells are able to initiate metastatic growth [104]. In line with these findings, high activity of the Notch3 receptor has been found in tumor vasculature [105]. In aberrant conditions, Jagged1is overexpressed in cancer cells, blocking endothelial apoptosis driven by Notch3 and promoting local angiogenesis [105-108].

Regulation of tumor vascularization is also central in the establishment of a hypoxic microenvironment favored by a subset of carcinomas (i.e. lung, breast, kidney and oral cancer) (Figure 3) [109-113].

Mammalian cells typically react to a reduced oxygen availability by activating transcription of HIF-1 factor to trigger angiogenesis [114]. The two existing isoforms of HIFa (HIF1a and HIF2a) translocate to the nucleus upon binding with the HIF-1b form, interact with the hypoxia 
binding elements and consequently promote the transcription of selective target genes. Activation of HIF has various implications in promoting tumorigenesis, including changes in metabolism and the production of oxygen radicals, maintenance of undifferentiation and induction of a motile phenotype acquisition via EMT [115]. Specifically, it directly correlates with advanced stages of oral cancer and it has been proposed as significant prognostic marker (Figure 3) [116]. In hypoxic conditions both Notch activity and expression of Notch-dependent target genes are increased. Crosstalk of hypoxia and Notch signaling has been activated implicated in EMT and results in an increase in the invasiveness of oral squamous cell carcinoma, although a full detailed mechanism of action remains to be described $[112,113$, $117,118]$

Therefore, Notch signaling is involved in the regulation of normoxia and physiological vasculature growth, with important consequences for therapeutical application. Treatment with cetuximab showed broad effects on both Notch activation and HIF sensitivity, inhibiting tumor-induced angiogenesis in a murine model for HNSCC [118].

\section{Notch in carcinoma: When context matters}

The Notch pathway is genetically altered in a large number of hematopoietic and solid tumors, resulting in aberrant activation or repression of the pathway. Different types of mutations interfere with receptor-ligand interaction, molecular regulation, gene targeting and epigenetic regulations [119-122].

In carcinomas, the role of epithelial Notch varies greatly depending on the organ affected [123125]. Emerging evidence suggests that the Notch signaling network is frequently deregulated in human malignancies, with up-regulated expression of Notch receptors and their ligands in head and neck, cervical, lung, colon, and pancreatic cancer supporting the idea that Notch promotes cancer development $[126,127]$. In a limited number of carcinomas, including skin 
cancer, human hepatocellular carcinoma and small cell lung cancer, Notch signaling has been shown to be anti-proliferative rather than oncogenic [124]. It is therefore essential to establish the context of analysis to define the function of epithelial Notch as either oncogenic or antiproliferative [123-125]. In the following paragraphs, we compare the role of Notch in a few relevant carcinomas, where its activity fluctuates significantly with its tumorigenic potential.

\section{$\underline{\text { Head and neck cancer }}$}

Due to the high heterogeneity of the HNSCC and the different types of tissues that group under the same name, the exact function of the Notch pathway in this type of tumor remains to be clarified. All Notch receptors can be found highly expressed in HNSCC samples and OSCC, where they activate downstream signaling through Hey1 [128]. Notch1 mutations are the second most common mutations found in head and neck carcinoma (HNSCC), suggesting an essential role of the pathway in the pathogenesis of the tumor. In an in-vitro model of HNSCC, inhibition of Notch3 decreased sphere formation and proliferation in parallel with the inhibition of the activated target genes Hey1, cMyc and CCND1 [1, 129].

In line with the oncogenic role of Notch1, its upregulation leads to resistance to chemotherapy treatments and inhibition of Notch reduces the undifferentiated portion of cells in the HNSCC [130, 131]. Dll4 overexpression can be found in subtypes of HNSCC, and appears to have a role in vasculature reorganization and risk of metastases, consequently resulting in poor prognosis [132]. Once activated, the Notch pathway increases the expression of target genes between normal mucosa and its dysplastic stage, with Hes1 and Hey1 being key players in the malignant condition [1]. The upregulation of Hes1 seems to also correlate with an increase in undifferentiation or an amplification of the stem cell population, as demonstrated by selfrenewal assay in spheres formation [133]. Several studies identified high levels of Notch1 expression in HNSCC, especially when considering the subset of OSCC [117]. Tongue cancer 
specifically displays an increased Notch3 expression that correlates with the degree of tumor progression, although cell proliferation does not appear to be altered [134]. High expression of Notch1 additionally correlates with high level of metastasis formation in patients with tongue cancer [135].

The Notch pathway is therefore relevant for HNSCC progression, although the exact mechanism of function remains to be identified.

\section{$\underline{\text { Breast cancer }}$}

Breast cancer is a form of cancer in which the Notch pathway may act as a both tumor suppressor as well as oncogene [136-138]. One of the first indications that Notch signaling may play a role in solid tumors came from experiments with mammary models developed after tissue infection with the mouse mammary tumor virus (MMTV). Integration of the MMTV genome next to the "Int-3" locus resulted in an activating mutation of Notch4, leading to the constitutive activation of the receptor and subsequent breast cancer development [139-141]. Recent observations indicate that Notch4 may play a more specific role compared to other Notch receptors in breast cancer stem cells [142] through signaling via other oncogenic pathways, such as Ras and Wnt [143-147].

Thus, Notch activation seems to play a pro-tumorigenic role in breast cancer [148-151]. However, recent studies indicate that hyper-activation of NOTCH3 may induce senescence in breast cancer cells and therefore have a detrimental effect on cancer development [152]. This apparent divergence of results might be explained by the fact that mammary epithelial cells respond differently to different levels of activation of the Notch pathway [153]. Consequently, different Notch receptors may have unique signaling outputs in mammary epithelial cells as well as producing alternative responses in different subtypes of breast cancers. 


\section{$\underline{\text { Colorectal cancer }}$}

The intestinal epithelium possesses an unprecedented self-renewal rate that appears to be linked to a high susceptibility to malignant transformation $[154,155]$. Notch signaling has been known to be involved in both the control of homeostatic self-renewal in stem cell populations and the development of colorectal cancer (CRC) [156-158]. While mutations of NOTCH genes are rare, regulators of the pathway are often affected (including FBXW7), resulting in an overall overexpression or uncontrolled activation of Notch signaling in CRC [155, 159-162]. In addition, Notch activation has been linked to activation of Wnt signaling and Hippo/YAP signaling in CRC cells, although the various levels of crosstalk between these pathways are still not fully understood [46, 47, 156, 163-166]. In particular, Jagged1, expressed on tumor cells themselves or produced from endothelial cells, is thought to be a key ligand for Notch activation in CRC cells $[47,108,163]$. Another Notch ligand, DLL4, plays a non-cell autonomous role in CRC development, in large part by controlling the development of blood vessels necessary for tumor growth $[167,168]$. Expression of miR-34a in CRC stem cells may help to control Notch output and generate a bimodal Notch response [169]. Finally, Notch signaling may play a crucial role not only in the early stages of CRC development by controlling the fate of stem cells and cancer stem cells, but also at the later stages of tumor invasion and metastasis [103].

\section{Cutaneous Squamous Cell Carcinoma (cSCC)}

Tumors arising from keratinized squamous epithelium can have different epidemiological associations, however they all derive from a disrupted differentiation of the basal progenitors, resulting in dysplastic epithelium and increased proliferation [170, 171]. Cutaneous squamous cell carcinomas (cSCC) often occur as a result of exposure to UV radiation, which results in genetic aberration, mostly ending in TP53 loss. The Notch pathway has been found to be 
inactive in cutaneous SCC malignancies, and instead works as a tumor suppressor under the control of p53 $[52,170]$. Notch1 and Notch2 mutations affecting the EGF repeats have been mapped in human cSCC and are linked to a dominant-negative phenotype [172, 173]. Similarly, murine models of conditional Notch1 or Notch2 deletions result in structural defects and tumor formation $[174,175]$.

The molecular mechanism triggered by Notch in this context is still partially unresolved, as are the elements tuning its activation towards a negative regulation of tumor growth, in contrast to other carcinomas, where the same pathway bears an oncogenic function.

\section{Lung adenocarcinoma}

Lung adenocarcinoma (LAC) is a major subtype of lung cancer [176-178]. In-vitro studies initially identified the Notch signaling pathway as a promoter of LAC cell proliferation [179181]. In parallel with these observations, in-vivo modelling confirmed the relevance of the Notch pathway in preserving LAC development and maintenance [176, 182, 183]. Specifically, the NOTCH3 receptor is crucial in regulating the self-renewal of LAC tumor-propagating cells [178]. LAC cells express the Jagged2 ligand on their surface and support the metastatic potential of LAC stem cells [184]. Thus, despite the absence of Notch mutations in LAC screenings, activation of Notch may be important in LAC growth and Notch activity correlates significantly with the worsening of survival in lung cancer patients [177, 178, 185].

The squamous cell lung carcinoma (lung SCC) is the second major type of non-small cell lung cancer. Upon mapping of human-derived lung-SCC samples, several loss of functions mutations were identified in the EGF-like repeats of the Notch1 receptor and result in a 
truncated, non-functional receptor. Therefore, in contrast to LAC, Notch may play a tumor suppressor role in the lung-SCC subtype of malignancy [170, 186-189].

Interestingly, as observed for cutaneous tumors, loss of Notch activity appears to be needed for growth of tumors in tissues derived from squamous differentiated epithelium. Thus, different subtypes of lung cancer display strikingly different roles for Notch signaling in cancer development, possibly depending on the type of cells involved, the crosstalk with other molecular pathway or the fine tuning of Notch activation in different biological context.

\section{Notch as therapeutic target}

Notch signaling is implicated in a variety of processes leading to cancer initiation, growth and progression, and has therefore been a focus for the development of novel therapies in the recent years.

As the Notch pathway requires a proteolytic cleavage by $\gamma$-secretase for the generation of its active intracellular form, small $\gamma$-secretase inhibitor (GSI) molecules have been developed to interfere with Notch1 activity (Figure 2). Unfortunately, testing in animal models and clinical trials has revealed a high gastrointestinal toxicity due to the accumulation of goblet cells in the intestine upon Notch-dependent induction of differentiation [190, 191]. Alternatively, a combination of treatment for GSI blockage and glucocorticoids mitigate intestinal side effects and control goblet cell metaplasia [192]. Other proteolytic enzymes, such as ADAM10/17, participate in pathway activation and are used as target molecules for $\alpha$-secretase inhibition (Figure 2) [193, 194]. A promising approach involves specific blockage of the receptor-ligand interaction, for which a strong knowledge of the basic biological processes is necessary. Antibodies against Notch1 and Notch2 receptors protect the intracellular domain from its own cleavage, inhibiting the release of NICN1 and NICN2 active molecules (Figure 2) [195]. 
Importantly, the molecular specificity of these antibodies reduces the intestinal side effects and, in particular, a blocking antibody against Notch1 showed promising results in inhibiting tumor growth [196]. As the function of the Notch pathway strongly relies on the specific interaction between receptor and ligand, whose type varies from system to system, the efficiency of blockers strongly depends on the analyzed tissue [197]. Similarly to the blocking antibodies, several synthetic peptides have been developed to inhibit Notch activation. They are mainly used for basic research studies, although a blocker of the Notch-coactivator MALM1 was found to have useful applications in the treatment of several models of human T-ALL by interfering with cell proliferation and leukemia progression (Figure 2) [198]. Finally, it might be of interest to alter the regulation of Notch turnover by interfering with its trafficking in the cancer cell secretory pathway (Figure 2) [199, 200].

An additional level of complication in the development of anti-Notch therapies is the condition in which Notch works as tumor-suppressor, as this varies significantly depending on the tissue analyzed, the type of receptor-ligand interaction and the degree of tumorigenic progression. Additional studies are needed to support the most adequate therapy in each case. In head and neck cancer the heterogeneity of the tissues affected increases the level of complexity in predicting which Notch receptor and ligand are most relevant to sustain the tumor. Mapping the expression and the level of activation of the pathway might be a valuable initial screening to determine the relevant molecules in each condition and their clinical interest. Finally, Notch agonists and antagonists could be used in combination with existing therapies to contrast tumor development.

\section{Conclusions}

To summarize, the Notch pathway plays an essential role in regulating major aspects of tumor emergence, maintenance and evolution into a more aggressive phenotype. It is involved in 
preserving the cellular elements that sustain carcinoma, the formation of a supportive microenvironment and their bilateral synergistic interaction. Although its effect varies greatly from system to system, Notch is central in head and neck malignancies, particularly in the most common and aggressive squamous cell carcinoma subtype. In order to improve our therapeutic approaches, we need a deeper molecular understanding of the function of the Notch pathway, including detailed knowledge of the pattern of expression in the heterogeneous population of tumor cells, genetic changes, transcript signatures and fine tuning of activity levels in a dynamic view that takes into consideration the evolution of the disease over time. 


\section{Figure Legends}

\section{Figure 1. Epithelia in the head and neck region}

Various types of epithelial tissue line the walls of head and neck structures (A). Mesenchyme and epithelia are divided by the ECM-rich basement membrane (brown line), in direct contact with the first layer of immature keratinocytes. Depending on the type of cells found, epithelial tissue is classified as stratified squamous epithelium, cuboidal epithelium, and columnar epithelium. Epithelia exposed to a continuous mechanical stress, such as masticatory mucosa and tongue epithelium (upper and middle left panels), contain an external layer of deposited keratins to function as protective layer. Simple columnar epithelium is found in the striated ducts of salivary glands (right lower panel), while the intercalated ducts are mainly formed by cuboidal epithelium (right middle panel). A specialized form of columnar epithelium is found in the respiratory epithelium of the nasal mucosa, where cilia work as both a physical barrier to pathogens and are actively engaged in their removal via beating motion.

\section{Figure 2. The Notch signalling: controlling steps at a glance}

The Notch signalling pathway is a complex pathway with various levels of regulation and finetuning. Initially, the immature Notch receptor faces a step-wise process of cleavage and glycosylation in the golgi apparatus, before being exposed to the plasma membrane as a functional molecule. On the cell surface, it interacts with a member of the Delta or Jagged family present on the surface of the juxtaposed cell. Ligands present on the surface of the same cell exposing Notch participate in a more complex level of regulation of the pathway, known as cis-inhibition (not depicted, for reviews [21, 201]). Activation of the pathway occurs upon receptor-ligand physical interaction, when the receptor undergoes a series of cleavages for the intracellular release of its active intracellular domain (NICD), which then transmigrates to the nucleus to join the complex for the activation of transcription of Notch-target genes. In the 
absence of the NICD, the complex works as a repressor of transcription. The NICD is additionally regulated by its transport in the endosomes and final lysosomes degradation, under the control of specialized inhibitor of Notch activity (such as NUMB).

\section{Figure 3: Notch regulates major elements in the head and neck tumor microenvironment}

The Notch pathway is involved in the maintenance of a healthy epithelium homeostasis (A) as well as central tumorigenic elements (B). It controls the balance between self-renewal and differentiation of stem cells in healthy conditions, as well as regulating the amplification of undifferentiated progenitors in the cancer core. It also participates in the process of EMT and its reverted MET, at the basis of invasiveness and metastases formation. Finally, it modulates the formation of an inflammatory milieu, inducing macrophage subtype specification and oxygen levels establishment in the tumour microenvironment. Depicted blue cells highlight the elements where Notch operates.

\section{Acknowledgements}

$\mathrm{CP}$, and TAM were supported by the UZH (University of Zurich). $\mathrm{CP}$ is a recipient of the Olga Mayenfisch Stiftung grant. The author would like to thank Christian Thomas Meisel and Alexandra Rose Noble for constructive criticism on the manuscript.

Conflict of interest: The authors declared no conflicts of interest with respect to the research, authorship, and/or publication of this article. 


\section{References}

1. Sun W, Gaykalova DA, Ochs MF, et al (2014) Activation of the NOTCH pathway in head and neck cancer. Cancer Res 74:1091-1104. https://doi.org/10.1158/00085472.CAN-13-1259

2. Mazur PK, Einwächter H, Lee M, et al (2010) Notch2 is required for progression of pancreatic intraepithelial neoplasia and development of pancreatic ductal adenocarcinoma. Proc Natl Acad Sci USA 107:13438-13443. https://doi.org/10.1073/pnas.1002423107

3. Maliekal TT, Bajaj J, Giri V, et al (2008) The role of Notch signaling in human cervical cancer: implications for solid tumors. Oncogene 27:5110-5114. https://doi.org/10.1038/onc.2008.224

4. Zagouras P, Stifani S, Blaumueller CM, et al (1995) Alterations in Notch signaling in neoplastic lesions of the human cervix. Proc Natl Acad Sci USA 92:6414-6418. https://doi.org/10.1073/pnas.92.14.6414

5. Rivera C (2015) Essentials of oral cancer. Int J Clin Exp Pathol 8:11884-11894

6. Bratman SV, Bruce JP, O’Sullivan B, et al (2016) Human Papillomavirus Genotype Association With Survival in Head and Neck Squamous Cell Carcinoma. JAMA Oncol 2:823-826. https://doi.org/10.1001/jamaoncol.2015.6587

7. Wang S-S, Tang Y-L, Pang X, et al (2019) The maintenance of an oral epithelial barrier. Life Sci 227:129-136. https://doi.org/10.1016/j.lfs.2019.04.029

8. Hunter KD, Parkinson EK, Harrison PR (2005) Profiling early head and neck cancer. Nat Rev Cancer 5:127-135. https://doi.org/10.1038/nrc1549

9. Brennan JA, Boyle JO, Koch WM, et al (1995) Association between cigarette smoking and mutation of the p53 gene in squamous-cell carcinoma of the head and neck. N Engl J Med 332:712-717. https://doi.org/10.1056/NEJM199503163321104

10. Bodily J, Laimins LA (2011) Persistence of human papillomavirus infection: keys to malignant progression. Trends Microbiol 19:33-39. https://doi.org/10.1016/j.tim.2010.10.002

11. Ferlay J, Soerjomataram I, Dikshit R, et al (2015) Cancer incidence and mortality worldwide: sources, methods and major patterns in GLOBOCAN 2012. Int J Cancer 136:E359-386. https://doi.org/10.1002/ijc.29210

12. Ndiaye C, Mena M, Alemany L, et al (2014) HPV DNA, E6/E7 mRNA, and p16INK4a detection in head and neck cancers: a systematic review and meta-analysis. Lancet Oncol 15:1319-1331. https://doi.org/10.1016/S1470-2045(14)70471-1

13. Wright JM, Soluk Tekkesin M (2017) Odontogenic tumors: where are we in 2017 ? J Istanb Univ Fac Dent 51:S10-S30. https://doi.org/10.17096/jiufd.52886 
14. Porcheri C, Mitsiadis TA (2019) Physiology, Pathology and Regeneration of Salivary Glands. Cells 8:. https://doi.org/10.3390/cells8090976

15. Winning TA, Townsend GC (2000) Oral mucosal embryology and histology. Clin Dermatol 18:499-511. https://doi.org/10.1016/s0738-081x(00)00140-1

16. Rothova M, Thompson H, Lickert H, Tucker AS (2012) Lineage tracing of the endoderm during oral development. Dev Dyn 241:1183-1191. https://doi.org/10.1002/dvdy.23804

17. Gilbert SF (2000) Developmental biology, 6th ed. Sinauer Associates, Sunderland, Mass

18. Siebel C, Lendahl U (2017) Notch Signaling in Development, Tissue Homeostasis, and Disease. Physiol Rev 97:1235-1294. https://doi.org/10.1152/physrev.00005.2017

19. Carbonell M B, Bayona R F, Garavito-Aguilar ZV, et al (2018) Hey1 gene expression patterns during the development of branchial arches and facial prominences. Rev MVZ Córdoba 6813-6825. https://doi.org/10.21897/rmvz.1370

20. Zhu X-J, Yuan X, Wang M, et al (2017) A Wnt/Notch/Pax7 signaling network supports tissue integrity in tongue development. J Biol Chem 292:9409-9419. https://doi.org/10.1074/jbc.M117.789438

21. Bigas A, Porcheri C (2018) Notch and Stem Cells. Adv Exp Med Biol 1066:235-263. https://doi.org/10.1007/978-3-319-89512-3_12

22. Fuchs E (2007) Scratching the surface of skin development. Nature 445:834-842. https://doi.org/10.1038/nature05659

23. Koster MI, Roop DR (2007) Mechanisms regulating epithelial stratification. Annu Rev Cell Dev Biol 23:93-113. https://doi.org/10.1146/annurev.cellbio.23.090506.123357

24. Wessells NK, Roessner KD (1965) Nonproliferation in dermal condensations of mouse vibrissae and pelage hairs. Developmental Biology 12:419-433. https://doi.org/10.1016/0012-1606(65)90007-2

25. Stuart ES, Moscona AA (1967) Embryonic Morphogenesis: Role of Fibrous Lattice in the Development of Feathers and Feather Patterns. Science 157:947-948. https://doi.org/10.1126/science.157.3791.947-a

26. Stuart ES, Garber B, Moscona AA (1972) An analysis of feather germ formation in the embryo andin vitro, in normal development and in skin treated with hydrocortisone. $\mathbf{J}$ Exp Zool 179:97-118. https://doi.org/10.1002/jez.1401790108

27. Holbrook KA, Vogel AM, Underwood RA, Foster CA (1988) Melanocytes in Human Embryonic and Fetal Skin: A Review and New Findings. Pigment Cell Res 1:6-17. https://doi.org/10.1111/j.1600-0749.1988.tb00789.x

28. Kopan R, Fuchs E (1989) The use of retinoic acid to probe the relation between hyperproliferation-associated keratins and cell proliferation in normal and malignant 
epidermal cells. The Journal of Cell Biology 109:295-307.

https://doi.org/10.1083/jcb.109.1.295

29. Tadeu AMB, Horsley V (2013) Notch signaling represses p63 expression in the developing surface ectoderm. Development 140:3777-3786.

https://doi.org/10.1242/dev.093948

30. Candi E, Schmidt R, Melino G (2005) The cornified envelope: a model of cell death in the skin. Nat Rev Mol Cell Biol 6:328-340. https://doi.org/10.1038/nrm1619

31. Leethanakul C, Patel V, Gillespie J, et al (2000) Distinct pattern of expression of differentiation and growth-related genes in squamous cell carcinomas of the head and neck revealed by the use of laser capture microdissection and cDNA arrays. Oncogene 19:3220-3224. https://doi.org/10.1038/sj.onc.1203703

32. Bolós V, Blanco M, Medina V, et al (2009) Notch signalling in cancer stem cells. Clin Transl Oncol 11:11-19. https://doi.org/10.1007/s12094-009-0305-2

33. Wang Z, Li Y, Banerjee S, Sarkar FH (2009) Emerging role of Notch in stem cells and cancer. Cancer Lett 279:8-12. https://doi.org/10.1016/j.canlet.2008.09.030

34. Bolós V, Grego-Bessa J, de la Pompa JL (2007) Notch signaling in development and cancer. Endocr Rev 28:339-363. https://doi.org/10.1210/er.2006-0046

35. Fan X, Matsui W, Khaki L, et al (2006) Notch pathway inhibition depletes stem-like cells and blocks engraftment in embryonal brain tumors. Cancer Res 66:7445-7452. https://doi.org/10.1158/0008-5472.CAN-06-0858

36. Liu S, Dontu G, Wicha MS (2005) Mammary stem cells, self-renewal pathways, and carcinogenesis. Breast Cancer Res 7:86-95. https://doi.org/10.1186/bcr1021

37. Dontu G, Jackson KW, McNicholas E, et al (2004) Role of Notch signaling in cell-fate determination of human mammary stem/progenitor cells. Breast Cancer Res 6:R605615. https://doi.org/10.1186/bcr920

38. Gal H, Amariglio N, Trakhtenbrot L, et al (2006) Gene expression profiles of AML derived stem cells; similarity to hematopoietic stem cells. Leukemia 20:2147-2154. https://doi.org/10.1038/sj.leu.2404401

39. Barakat SMM, Siar CH (2015) Differential expression of stem cell-like proteins in normal, hyperplastic and dysplastic oral epithelium. J Appl Oral Sci 23:79-86. https://doi.org/10.1590/1678-775720140245

40. Sawangarun W, Mandasari M, Aida J, et al (2018) Loss of Notch1 predisposes oroesophageal epithelium to tumorigenesis. Exp Cell Res 372:129-140. https://doi.org/10.1016/j.yexcr.2018.09.019

41. Lee SH, Do SI, Lee HJ, et al (2016) Notch1 signaling contributes to stemness in head and neck squamous cell carcinoma. Lab Invest 96:508-516.

https://doi.org/10.1038/labinvest.2015.163 
42. Stanger BZ, Datar R, Murtaugh LC, Melton DA (2005) Direct regulation of intestinal fate by Notch. Proc Natl Acad Sci USA 102:12443-12448.

https://doi.org/10.1073/pnas.0505690102

43. Guilmeau S (2012) Notch signaling and intestinal cancer. Adv Exp Med Biol 727:272288. https://doi.org/10.1007/978-1-4614-0899-4_21

44. Kazanjian A, Shroyer NF (2011) NOTCH Signaling and ATOH1 in Colorectal Cancers. Curr Colorectal Cancer Rep 7:121-127. https://doi.org/10.1007/s11888-0110090-5

45. Ueo T, Imayoshi I, Kobayashi T, et al (2012) The role of Hes genes in intestinal development, homeostasis and tumor formation. Development 139:1071-1082. https://doi.org/10.1242/dev.069070

46. Peignon G, Durand A, Cacheux W, et al (2011) Complex interplay between $\beta$-catenin signalling and Notch effectors in intestinal tumorigenesis. Gut 60:166-176. https://doi.org/10.1136/gut.2009.204719

47. Rodilla V, Villanueva A, Obrador-Hevia A, et al (2009) Jagged1 is the pathological link between Wnt and Notch pathways in colorectal cancer. Proc Natl Acad Sci USA 106:6315-6320. https://doi.org/10.1073/pnas.0813221106

48. Nicolas M, Wolfer A, Raj K, et al (2003) Notch1 functions as a tumor suppressor in mouse skin. Nat Genet 33:416-421. https://doi.org/10.1038/ng1099

49. Okuyama R, Nguyen B-C, Talora C, et al (2004) High commitment of embryonic keratinocytes to terminal differentiation through a Notch1-caspase 3 regulatory mechanism. Dev Cell 6:551-562. https://doi.org/10.1016/s1534-5807(04)00098-x

50. Estrach S, Cordes R, Hozumi K, et al (2008) Role of the Notch ligand Delta1 in embryonic and adult mouse epidermis. J Invest Dermatol 128:825-832.

https://doi.org/10.1038/sj.jid.5701113

51. Blanpain C, Fuchs E (2006) Epidermal stem cells of the skin. Annu Rev Cell Dev Biol 22:339-373. https://doi.org/10.1146/annurev.cellbio.22.010305.104357

52. Lefort K, Mandinova A, Ostano P, et al (2007) Notch1 is a p53 target gene involved in human keratinocyte tumor suppression through negative regulation of ROCK1/2 and MRCKalpha kinases. Genes Dev 21:562-577. https://doi.org/10.1101/gad.1484707

53. Estrach S, Ambler CA, Lo Celso C, et al (2006) Jagged 1 is a beta-catenin target gene required for ectopic hair follicle formation in adult epidermis. Development 133:44274438. https://doi.org/10.1242/dev.02644

54. Phillips TM, McBride WH, Pajonk F (2006) The response of CD24(-/low)/CD44+ breast cancer-initiating cells to radiation. J Natl Cancer Inst 98:1777-1785. https://doi.org/10.1093/jnci/djj495

55. Wang J, Wakeman TP, Lathia JD, et al (2010) Notch promotes radioresistance of glioma stem cells. Stem Cells 28:17-28. https://doi.org/10.1002/stem.261 
56. Christiansen JJ, Rajasekaran AK (2006) Reassessing epithelial to mesenchymal transition as a prerequisite for carcinoma invasion and metastasis. Cancer Res 66:8319-8326. https://doi.org/10.1158/0008-5472.CAN-06-0410

57. Klymkowsky MW, Savagner P (2009) Epithelial-mesenchymal transition: a cancer researcher's conceptual friend and foe. Am J Pathol 174:1588-1593. https://doi.org/10.2353/ajpath.2009.080545

58. Moreno-Bueno G, Portillo F, Cano A (2008) Transcriptional regulation of cell polarity in EMT and cancer. Oncogene 27:6958-6969. https://doi.org/10.1038/onc.2008.346

59. Wang Z, Li Y, Kong D, Sarkar FH (2010) The role of Notch signaling pathway in epithelial-mesenchymal transition (EMT) during development and tumor aggressiveness. Curr Drug Targets 11:745-751. https://doi.org/10.2174/138945010791170860

60. Becker K-F, Rosivatz E, Blechschmidt K, et al (2007) Analysis of the E-cadherin repressor Snail in primary human cancers. Cells Tissues Organs (Print) 185:204-212. https://doi.org/10.1159/000101321

61. Timmerman LA, Grego-Bessa J, Raya A, et al (2004) Notch promotes epithelialmesenchymal transition during cardiac development and oncogenic transformation. Genes Dev 18:99-115. https://doi.org/10.1101/gad.276304

62. Niessen K, Fu Y, Chang L, et al (2008) Slug is a direct Notch target required for initiation of cardiac cushion cellularization. J Cell Biol 182:315-325. https://doi.org/10.1083/jcb.200710067

63. Sahlgren C, Gustafsson MV, Jin S, et al (2008) Notch signaling mediates hypoxiainduced tumor cell migration and invasion. Proc Natl Acad Sci USA 105:6392-6397. https://doi.org/10.1073/pnas.0802047105

64. Brabletz T, Kalluri R, Nieto MA, Weinberg RA (2018) EMT in cancer. Nat Rev Cancer 18:128-134. https://doi.org/10.1038/nrc.2017.118

65. Hüsemann Y, Geigl JB, Schubert F, et al (2008) Systemic spread is an early step in breast cancer. Cancer Cell 13:58-68. https://doi.org/10.1016/j.ccr.2007.12.003

66. Klein CA (2013) Selection and adaptation during metastatic cancer progression. Nature 501:365-372. https://doi.org/10.1038/nature12628

67. Mareel M, Vleminckx K, Vermeulen S, et al (1992) E-cadherin expression: a counterbalance for cancer cell invasion. Bull Cancer 79:347-355

68. Birchmeier W, Behrens J (1994) Cadherin expression in carcinomas: role in the formation of cell junctions and the prevention of invasiveness. Biochim Biophys Acta 1198:11-26. https://doi.org/10.1016/0304-419x(94)90003-5

69. Tsai JH, Donaher JL, Murphy DA, et al (2012) Spatiotemporal regulation of epithelialmesenchymal transition is essential for squamous cell carcinoma metastasis. Cancer Cell 22:725-736. https://doi.org/10.1016/j.ccr.2012.09.022 
70. Krishnamachary B, Zagzag D, Nagasawa H, et al (2006) Hypoxia-inducible factor-1dependent repression of E-cadherin in von Hippel-Lindau tumor suppressor-null renal cell carcinoma mediated by TCF3, ZFHX1A, and ZFHX1B. Cancer Res 66:27252731. https://doi.org/10.1158/0008-5472.CAN-05-3719

71. Esteban MA, Tran MGB, Harten SK, et al (2006) Regulation of E-cadherin expression by VHL and hypoxia-inducible factor. Cancer Res 66:3567-3575. https://doi.org/10.1158/0008-5472.CAN-05-2670

72. Wang Z, Li Y, Kong D, et al (2009) Acquisition of epithelial-mesenchymal transition phenotype of gemcitabine-resistant pancreatic cancer cells is linked with activation of the notch signaling pathway. Cancer Res 69:2400-2407. https://doi.org/10.1158/00085472.CAN-08-4312

73. Fuchs BC, Fujii T, Dorfman JD, et al (2008) Epithelial-to-mesenchymal transition and integrin-linked kinase mediate sensitivity to epidermal growth factor receptor inhibition in human hepatoma cells. Cancer Res 68:2391-2399. https://doi.org/10.1158/0008-5472.CAN-07-2460

74. Cheng GZ, Chan J, Wang Q, et al (2007) Twist transcriptionally up-regulates AKT2 in breast cancer cells leading to increased migration, invasion, and resistance to paclitaxel. Cancer Res 67:1979-1987. https://doi.org/10.1158/0008-5472.CAN-061479

75. Sabbah M, Emami S, Redeuilh G, et al (2008) Molecular signature and therapeutic perspective of the epithelial-to-mesenchymal transitions in epithelial cancers. Drug Resist Updat 11:123-151. https://doi.org/10.1016/j.drup.2008.07.001

76. Meurette O, Mehlen P (2018) Notch Signaling in the Tumor Microenvironment. Cancer Cell 34:536-548. https://doi.org/10.1016/j.ccell.2018.07.009

77. Qian B-Z, Li J, Zhang H, et al (2011) CCL2 recruits inflammatory monocytes to facilitate breast-tumour metastasis. Nature 475:222-225.

https://doi.org/10.1038/nature10138

78. Cassetta L, Fragkogianni S, Sims AH, et al (2019) Human Tumor-Associated Macrophage and Monocyte Transcriptional Landscapes Reveal Cancer-Specific Reprogramming, Biomarkers, and Therapeutic Targets. Cancer Cell 35:588-602.e10. https://doi.org/10.1016/j.ccell.2019.02.009

79. Cassetta L, Noy R, Swierczak A, et al (2016) Isolation of Mouse and Human TumorAssociated Macrophages. Adv Exp Med Biol 899:211-229. https://doi.org/10.1007/978-3-319-26666-4_12

80. Zhang Q, Liu L, Gong C, et al (2012) Prognostic significance of tumor-associated macrophages in solid tumor: a meta-analysis of the literature. PLoS ONE 7:e50946. https://doi.org/10.1371/journal.pone.0050946

81. Lee C-H, Liu S-Y, Chou K-C, et al (2014) Tumor-associated macrophages promote oral cancer progression through activation of the Axl signaling pathway. Ann Surg Oncol 21:1031-1037. https://doi.org/10.1245/s10434-013-3400-0 
82. Hu Y, He M-Y, Zhu L-F, et al (2016) Tumor-associated macrophages correlate with the clinicopathological features and poor outcomes via inducing epithelial to mesenchymal transition in oral squamous cell carcinoma. J Exp Clin Cancer Res 35:12. https://doi.org/10.1186/s13046-015-0281-z

83. Evrard D, Szturz P, Tijeras-Raballand A, et al (2019) Macrophages in the microenvironment of head and neck cancer: potential targets for cancer therapy. Oral Oncol 88:29-38. https://doi.org/10.1016/j.oraloncology.2018.10.040

84. Lee C-C, Lin J-C, Hwang W-L, et al (2018) Macrophage-secreted interleukin-35 regulates cancer cell plasticity to facilitate metastatic colonization. Nat Commun 9:3763. https://doi.org/10.1038/s41467-018-06268-0

85. Marcus B, Arenberg D, Lee J, et al (2004) Prognostic factors in oral cavity and oropharyngeal squamous cell carcinoma. Cancer 101:2779-2787.

https://doi.org/10.1002/cncr.20701

86. Fujii N, Shomori K, Shiomi T, et al (2012) Cancer-associated fibroblasts and CD163positive macrophages in oral squamous cell carcinoma: their clinicopathological and prognostic significance. J Oral Pathol Med 41:444-451. https://doi.org/10.1111/j.16000714.2012.01127.x

87. He K-F, Zhang L, Huang C-F, et al (2014) CD163+ tumor-associated macrophages correlated with poor prognosis and cancer stem cells in oral squamous cell carcinoma. Biomed Res Int 2014:838632. https://doi.org/10.1155/2014/838632

88. Klinakis A, Lobry C, Abdel-Wahab O, et al (2011) A novel tumour-suppressor function for the Notch pathway in myeloid leukaemia. Nature 473:230-233. https://doi.org/10.1038/nature09999

89. Palaga T, Buranaruk C, Rengpipat S, et al (2008) Notch signaling is activated by TLR stimulation and regulates macrophage functions. Eur J Immunol 38:174-183. https://doi.org/10.1002/eji.200636999

90. Ando K, Kanazawa S, Tetsuka T, et al (2003) Induction of Notch signaling by tumor necrosis factor in rheumatoid synovial fibroblasts. Oncogene 22:7796-7803. https://doi.org/10.1038/sj.onc.1206965

91. Espinosa L, Cathelin S, D'Altri T, et al (2010) The Notch/Hes1 pathway sustains NF$\kappa \mathrm{B}$ activation through CYLD repression in T cell leukemia. Cancer Cell 18:268-281. https://doi.org/10.1016/j.ccr.2010.08.006

92. Franklin RA, Liao W, Sarkar A, et al (2014) The cellular and molecular origin of tumor-associated macrophages. Science 344:921-925.

https://doi.org/10.1126/science. 1252510

93. Liu H, Wang J, Zhang M, et al (2017) Jagged1 promotes aromatase inhibitor resistance by modulating tumor-associated macrophage differentiation in breast cancer patients. Breast Cancer Res Treat 166:95-107. https://doi.org/10.1007/s10549-017-4394-2 
94. Mao L, Zhao Z-L, Yu G-T, et al (2018) $\gamma$-Secretase inhibitor reduces immunosuppressive cells and enhances tumour immunity in head and neck squamous cell carcinoma. Int J Cancer 142:999-1009. https://doi.org/10.1002/ijc.31115

95. Wang Y-C, He F, Feng F, et al (2010) Notch signaling determines the M1 versus M2 polarization of macrophages in antitumor immune responses. Cancer Res 70:48404849. https://doi.org/10.1158/0008-5472.CAN-10-0269

96. Nywening TM, Wang-Gillam A, Sanford DE, et al (2016) Targeting tumour-associated macrophages with CCR2 inhibition in combination with FOLFIRINOX in patients with borderline resectable and locally advanced pancreatic cancer: a single-centre, open-label, dose-finding, non-randomised, phase 1b trial. Lancet Oncol 17:651-662. https://doi.org/10.1016/S1470-2045(16)00078-4

97. Edelman MJ, Watson D, Wang X, et al (2008) Eicosanoid modulation in advanced lung cancer: cyclooxygenase-2 expression is a positive predictive factor for celecoxib + chemotherapy--Cancer and Leukemia Group B Trial 30203. J Clin Oncol 26:848855. https://doi.org/10.1200/JCO.2007.13.8081

98. Coward J, Kulbe H, Chakravarty P, et al (2011) Interleukin-6 as a therapeutic target in human ovarian cancer. Clin Cancer Res 17:6083-6096. https://doi.org/10.1158/10780432.CCR-11-0945

99. Hellström M, Phng L-K, Hofmann JJ, et al (2007) Dll4 signalling through Notch1 regulates formation of tip cells during angiogenesis. Nature 445:776-780. https://doi.org/10.1038/nature05571

100. Benedito R, Hellström M (2013) Notch as a hub for signaling in angiogenesis. Exp Cell Res 319:1281-1288. https://doi.org/10.1016/j.yexcr.2013.01.010

101. Benedito R, Roca C, Sörensen I, et al (2009) The notch ligands Dll4 and Jagged1 have opposing effects on angiogenesis. Cell 137:1124-1135. https://doi.org/10.1016/j.cell.2009.03.025

102. Pedrosa A-R, Trindade A, Carvalho C, et al (2015) Endothelial Jagged1 promotes solid tumor growth through both pro-angiogenic and angiocrine functions. Oncotarget 6:24404-24423. https://doi.org/10.18632/oncotarget.4380

103. Sonoshita M, Aoki M, Fuwa H, et al (2011) Suppression of colon cancer metastasis by Aes through inhibition of Notch signaling. Cancer Cell 19:125-137. https://doi.org/10.1016/j.ccr.2010.11.008

104. Ghajar CM, Peinado H, Mori H, et al (2013) The perivascular niche regulates breast tumour dormancy. Nat Cell Biol 15:807-817. https://doi.org/10.1038/ncb2767

105. Lin S, Negulescu A, Bulusu S, et al (2017) Non-canonical NOTCH3 signalling limits tumour angiogenesis. Nat Commun 8:16074. https://doi.org/10.1038/ncomms16074

106. Su Q, Zhang B, Zhang L, et al (2017) Jagged1 upregulation in prostate epithelial cells promotes formation of reactive stroma in the Pten null mouse model for prostate cancer. Oncogene 36:618-627. https://doi.org/10.1038/onc.2016.232 
107. Zeng Q, Li S, Chepeha DB, et al (2005) Crosstalk between tumor and endothelial cells promotes tumor angiogenesis by MAPK activation of Notch signaling. Cancer Cell 8:13-23. https://doi.org/10.1016/j.ccr.2005.06.004

108. Lu J, Ye X, Fan F, et al (2013) Endothelial cells promote the colorectal cancer stem cell phenotype through a soluble form of Jagged-1. Cancer Cell 23:171-185. https://doi.org/10.1016/j.ccr.2012.12.021

109. Al Tameemi W, Dale TP, Al-Jumaily RMK, Forsyth NR (2019) Hypoxia-Modified Cancer Cell Metabolism. Front Cell Dev Biol 7:4. https://doi.org/10.3389/fcell.2019.00004

110. Giatromanolaki A, Liousia M, Arelaki S, et al (2017) Differential effect of hypoxia and acidity on lung cancer cell and fibroblast metabolism. Biochem Cell Biol 95:428-436. https://doi.org/10.1139/bcb-2016-0197

111. Chappell JC, Payne LB, Rathmell WK (2019) Hypoxia, angiogenesis, and metabolism in the hereditary kidney cancers. J Clin Invest 129:442-451. https://doi.org/10.1172/JCI120855

112. Kujan O, Shearston K, Farah CS (2017) The role of hypoxia in oral cancer and potentially malignant disorders: a review. J Oral Pathol Med 46:246-252. https://doi.org/10.1111/jop.12488

113. De Francesco EM, Maggiolini M, Musti AM (2018) Crosstalk between Notch, HIF-1 $\alpha$ and GPER in Breast Cancer EMT. Int J Mol Sci 19:. https://doi.org/10.3390/ijms19072011

114. Manalo DJ, Rowan A, Lavoie T, et al (2005) Transcriptional regulation of vascular endothelial cell responses to hypoxia by HIF-1. Blood 105:659-669. https://doi.org/10.1182/blood-2004-07-2958

115. Semenza GL (2012) Hypoxia-inducible factors: mediators of cancer progression and targets for cancer therapy. Trends Pharmacol Sci 33:207-214. https://doi.org/10.1016/j.tips.2012.01.005

116. Qian J, Wenguang X, Zhiyong W, et al (2016) Hypoxia inducible factor: a potential prognostic biomarker in oral squamous cell carcinoma. Tumour Biol 37:10815-10820. https://doi.org/10.1007/s13277-016-4976-3

117. Yoshida R, Nagata M, Nakayama H, et al (2013) The pathological significance of Notch1 in oral squamous cell carcinoma. Lab Invest 93:1068-1081. https://doi.org/10.1038/labinvest.2013.95

118. Wang W-M, Zhao Z-L, Ma S-R, et al (2015) Epidermal growth factor receptor inhibition reduces angiogenesis via hypoxia-inducible factor- $1 \alpha$ and Notch1 in head neck squamous cell carcinoma. PLoS ONE 10:e0119723. https://doi.org/10.1371/journal.pone.0119723

119. Haines N, Irvine KD (2003) Glycosylation regulates Notch signalling. Nat Rev Mol Cell Biol 4:786-797. https://doi.org/10.1038/nrm1228 
120. Lei L, Xu A, Panin VM, Irvine KD (2003) An O-fucose site in the ligand binding domain inhibits Notch activation. Development 130:6411-6421. https://doi.org/10.1242/dev.00883

121. Ntziachristos P, Lim JS, Sage J, Aifantis I (2014) From fly wings to targeted cancer therapies: a centennial for notch signaling. Cancer Cell 25:318-334. https://doi.org/10.1016/j.ccr.2014.02.018

122. Okajima T, Xu A, Irvine KD (2003) Modulation of notch-ligand binding by protein Ofucosyltransferase 1 and fringe. J Biol Chem 278:42340-42345.

https://doi.org/10.1074/jbc.M308687200

123. Kopan R, Ilagan MXG (2009) The canonical Notch signaling pathway: unfolding the activation mechanism. Cell 137:216-233. https://doi.org/10.1016/j.cell.2009.03.045

124. Dotto GP (2008) Notch tumor suppressor function. Oncogene 27:5115-5123. https://doi.org/10.1038/onc.2008.225

125. Dufraine J, Funahashi Y, Kitajewski J (2008) Notch signaling regulates tumor angiogenesis by diverse mechanisms. Oncogene 27:5132-5137.

https://doi.org/10.1038/onc.2008.227

126. Miele L, Osborne B (1999) Arbiter of differentiation and death: Notch signaling meets apoptosis. J Cell Physiol 181:393-409. https://doi.org/10.1002/(SICI)10974652(199912)181:3<393::AID-JCP3>3.0.CO;2-6

127. Miele L, Miao H, Nickoloff BJ (2006) NOTCH signaling as a novel cancer therapeutic target. Curr Cancer Drug Targets 6:313-323. https://doi.org/10.2174/156800906777441771

128. Cancer Genome Atlas Network (2015) Comprehensive genomic characterization of head and neck squamous cell carcinomas. Nature 517:576-582.

https://doi.org/10.1038/nature14129

129. Man C-H, Wei-Man Lun S, Wai-Ying Hui J, et al (2012) Inhibition of NOTCH3 signalling significantly enhances sensitivity to cisplatin in EBV-associated nasopharyngeal carcinoma. J Pathol 226:471-481. https://doi.org/10.1002/path.2997

130. Gu F, Ma Y, Zhang Z, et al (2010) Expression of Stat3 and Notch1 is associated with cisplatin resistance in head and neck squamous cell carcinoma. Oncol Rep 23:671676. https://doi.org/10.3892/or_00000683

131. Zhao Z-L, Zhang L, Huang C-F, et al (2016) NOTCH1 inhibition enhances the efficacy of conventional chemotherapeutic agents by targeting head neck cancer stem cell. Sci Rep 6:24704. https://doi.org/10.1038/srep24704

132. Lin J-T, Chen M-K, Yeh K-T, et al (2010) Association of high levels of Jagged-1 and Notch-1 expression with poor prognosis in head and neck cancer. Ann Surg Oncol 17:2976-2983. https://doi.org/10.1245/s10434-010-1118-9 
133. Lee SH, Hong HS, Liu ZX, et al (2012) TNF $\alpha$ enhances cancer stem cell-like phenotype via Notch-Hes1 activation in oral squamous cell carcinoma cells. Biochem Biophys Res Commun 424:58-64. https://doi.org/10.1016/j.bbrc.2012.06.065

134. Zhang T-H, Liu H-C, Zhu L-J, et al (2011) Activation of Notch signaling in human tongue carcinoma. J Oral Pathol Med 40:37-45. https://doi.org/10.1111/j.16000714.2010.00931.x

135. Joo Y-H, Jung C-K, Kim M-S, Sun D-I (2009) Relationship between vascular endothelial growth factor and Notch1 expression and lymphatic metastasis in tongue cancer. Otolaryngol Head Neck Surg 140:512-518. https://doi.org/10.1016/j.otohns.2008.12.057

136. Fu Y-P, Edvardsen H, Kaushiva A, et al (2010) NOTCH2 in breast cancer: association of SNP rs11249433 with gene expression in ER-positive breast tumors without TP53 mutations. Mol Cancer 9:113. https://doi.org/10.1186/1476-4598-9-113

137. Imatani A, Callahan R (2000) Identification of a novel NOTCH-4/INT-3 RNA species encoding an activated gene product in certain human tumor cell lines. Oncogene 19:223-231. https://doi.org/10.1038/sj.onc.1203295

138. Jhappan C, Gallahan D, Stahle C, et al (1992) Expression of an activated Notch-related int-3 transgene interferes with cell differentiation and induces neoplastic transformation in mammary and salivary glands. Genes Dev 6:345-355. https://doi.org/10.1101/gad.6.3.345

139. Gallahan D, Callahan R (1997) The mouse mammary tumor associated gene INT3 is a unique member of the NOTCH gene family (NOTCH4). Oncogene 14:1883-1890. https://doi.org/10.1038/sj.onc.1201035

140. Jarriault S, Brou C, Logeat F, et al (1995) Signalling downstream of activated mammalian Notch. Nature 377:355-358. https://doi.org/10.1038/377355a0

141. Robbins J, Blondel BJ, Gallahan D, Callahan R (1992) Mouse mammary tumor gene int-3: a member of the notch gene family transforms mammary epithelial cells. J Virol 66:2594-2599

142. Harrison H, Farnie G, Howell SJ, et al (2010) Regulation of breast cancer stem cell activity by signaling through the Notch4 receptor. Cancer Res 70:709-718. https://doi.org/10.1158/0008-5472.CAN-09-1681

143. Ayyanan A, Civenni G, Ciarloni L, et al (2006) Increased Wnt signaling triggers oncogenic conversion of human breast epithelial cells by a Notch-dependent mechanism. Proc Natl Acad Sci USA 103:3799-3804. https://doi.org/10.1073/pnas.0600065103

144. Fitzgerald K, Harrington A, Leder P (2000) Ras pathway signals are required for notch-mediated oncogenesis. Oncogene 19:4191-4198. https://doi.org/10.1038/sj.onc.1203766

145. Izrailit J, Berman HK, Datti A, et al (2013) High throughput kinase inhibitor screens reveal TRB3 and MAPK-ERK/TGF $\beta$ pathways as fundamental Notch regulators in 
breast cancer. Proc Natl Acad Sci USA 110:1714-1719.

https://doi.org/10.1073/pnas.1214014110

146. Meurette O, Stylianou S, Rock R, et al (2009) Notch activation induces Akt signaling via an autocrine loop to prevent apoptosis in breast epithelial cells. Cancer Res 69:5015-5022. https://doi.org/10.1158/0008-5472.CAN-08-3478

147. Weijzen S, Rizzo P, Braid M, et al (2002) Activation of Notch-1 signaling maintains the neoplastic phenotype in human Ras-transformed cells. Nat Med 8:979-986. https://doi.org/10.1038/nm754

148. Colaluca IN, Tosoni D, Nuciforo P, et al (2008) NUMB controls p53 tumour suppressor activity. Nature 451:76-80. https://doi.org/10.1038/nature06412

149. Pece S, Serresi M, Santolini E, et al (2004) Loss of negative regulation by Numb over Notch is relevant to human breast carcinogenesis. J Cell Biol 167:215-221. https://doi.org/10.1083/jcb.200406140

150. Robinson DR, Kalyana-Sundaram S, Wu Y-M, et al (2011) Functionally recurrent rearrangements of the MAST kinase and Notch gene families in breast cancer. Nat Med 17:1646-1651. https://doi.org/10.1038/nm.2580

151. Xu K, Usary J, Kousis PC, et al (2012) Lunatic fringe deficiency cooperates with the Met/Caveolin gene amplicon to induce basal-like breast cancer. Cancer Cell 21:626641. https://doi.org/10.1016/j.ccr.2012.03.041

152. Cui H, Kong Y, Xu M, Zhang H (2013) Notch3 functions as a tumor suppressor by controlling cellular senescence. Cancer Res 73:3451-3459.

https://doi.org/10.1158/0008-5472.CAN-12-3902

153. Mazzone M, Selfors LM, Albeck J, et al (2010) Dose-dependent induction of distinct phenotypic responses to Notch pathway activation in mammary epithelial cells. Proc Natl Acad Sci USA 107:5012-5017. https://doi.org/10.1073/pnas.1000896107

154. Legato MJ, Weintraub M, McCord GM, Morikawa Y (1991) The morphology of the developing canine conducting system: bundle branch and Purkinje cell architecture from birth to week 12 of life. J Mol Cell Cardiol 23:1063-1076. https://doi.org/10.1016/0022-2828(91)91641-4

155. Miyaki M, Yamaguchi T, Iijima T, et al (2009) Somatic mutations of the CDC4 (FBXW7) gene in hereditary colorectal tumors. Oncology 76:430-434. https://doi.org/10.1159/000217811

156. Fre S, Huyghe M, Mourikis $P$, et al (2005) Notch signals control the fate of immature progenitor cells in the intestine. Nature 435:964-968. https://doi.org/10.1038/nature03589

157. Radtke F, Clevers H (2005) Self-renewal and cancer of the gut: two sides of a coin. Science 307:1904-1909. https://doi.org/10.1126/science.1104815 
158. van Es JH, van Gijn ME, Riccio O, et al (2005) Notch/gamma-secretase inhibition turns proliferative cells in intestinal crypts and adenomas into goblet cells. Nature 435:959-963. https://doi.org/10.1038/nature03659

159. Babaei-Jadidi R, Li N, Saadeddin A, et al (2011) FBXW7 influences murine intestinal homeostasis and cancer, targeting Notch, Jun, and DEK for degradation. J Exp Med 208:295-312. https://doi.org/10.1084/jem.20100830

160. Camps J, Pitt JJ, Emons G, et al (2013) Genetic amplification of the NOTCH modulator LNX2 upregulates the WNT/ $\beta$-catenin pathway in colorectal cancer. Cancer Res 73:2003-2013. https://doi.org/10.1158/0008-5472.CAN-12-3159

161. Sancho R, Jandke A, Davis H, et al (2010) F-box and WD repeat domain-containing 7 regulates intestinal cell lineage commitment and is a haploinsufficient tumor suppressor. Gastroenterology 139:929-941. https://doi.org/10.1053/j.gastro.2010.05.078

162. Zhu J, Wang J, Shi Z, et al (2013) Deciphering genomic alterations in colorectal cancer through transcriptional subtype-based network analysis. PLoS ONE 8:e79282. https://doi.org/10.1371/journal.pone.0079282

163. Tschaharganeh DF, Chen X, Latzko P, et al (2013) Yes-associated protein up-regulates Jagged-1 and activates the Notch pathway in human hepatocellular carcinoma. Gastroenterology 144:1530-1542.e12. https://doi.org/10.1053/j.gastro.2013.02.009

164. Camargo FD, Gokhale S, Johnnidis JB, et al (2007) YAP1 increases organ size and expands undifferentiated progenitor cells. Curr Biol 17:2054-2060.

https://doi.org/10.1016/j.cub.2007.10.039

165. Kim H-A, Koo B-K, Cho J-H, et al (2012) Notch1 counteracts WNT/ $\beta$-catenin signaling through chromatin modification in colorectal cancer. J Clin Invest 122:3248 3259. https://doi.org/10.1172/JCI61216

166. Kwon C, Cheng P, King IN, et al (2011) Notch post-translationally regulates $\beta$-catenin protein in stem and progenitor cells. Nat Cell Biol 13:1244-1251. https://doi.org/10.1038/ncb2313

167. Fischer M, Yen W-C, Kapoun AM, et al (2011) Anti-DLL4 inhibits growth and reduces tumor-initiating cell frequency in colorectal tumors with oncogenic KRAS mutations. Cancer Res 71:1520-1525. https://doi.org/10.1158/0008-5472.CAN-102817

168. Ridgway J, Zhang G, Wu Y, et al (2006) Inhibition of Dll4 signalling inhibits tumour growth by deregulating angiogenesis. Nature 444:1083-1087. https://doi.org/10.1038/nature05313

169. Bu P, Chen K-Y, Chen JH, et al (2013) A microRNA miR-34a-regulated bimodal switch targets Notch in colon cancer stem cells. Cell Stem Cell 12:602-615. https://doi.org/10.1016/j.stem.2013.03.002 
170. Wang NJ, Sanborn Z, Arnett KL, et al (2011) Loss-of-function mutations in Notch receptors in cutaneous and lung squamous cell carcinoma. Proc Natl Acad Sci USA 108:17761-17766. https://doi.org/10.1073/pnas.1114669108

171. Nowell C, Radtke F (2013) Cutaneous Notch signaling in health and disease. Cold Spring Harb Perspect Med 3:a017772. https://doi.org/10.1101/cshperspect.a017772

172. Rebay I, Fehon RG, Artavanis-Tsakonas S (1993) Specific truncations of Drosophila Notch define dominant activated and dominant negative forms of the receptor. Cell 74:319-329. https://doi.org/10.1016/0092-8674(93)90423-n

173. Rebay I, Fleming RJ, Fehon RG, et al (1991) Specific EGF repeats of Notch mediate interactions with Delta and Serrate: implications for Notch as a multifunctional receptor. Cell 67:687-699. https://doi.org/10.1016/0092-8674(91)90064-6

174. Demehri S, Turkoz A, Kopan R (2009) Epidermal Notch1 loss promotes skin tumorigenesis by impacting the stromal microenvironment. Cancer Cell 16:55-66. https://doi.org/10.1016/j.ccr.2009.05.016

175. Dumortier A, Durham A-D, Di Piazza M, et al (2010) Atopic dermatitis-like disease and associated lethal myeloproliferative disorder arise from loss of Notch signaling in the murine skin. PLoS ONE 5:e9258. https://doi.org/10.1371/journal.pone.0009258

176. Licciulli S, Avila JL, Hanlon L, et al (2013) Notch1 is required for Kras-induced lung adenocarcinoma and controls tumor cell survival via p53. Cancer Res 73:5974-5984. https://doi.org/10.1158/0008-5472.CAN-13-1384

177. Westhoff B, Colaluca IN, D'Ario G, et al (2009) Alterations of the Notch pathway in lung cancer. Proc Natl Acad Sci USA 106:22293-22298.

https://doi.org/10.1073/pnas.0907781106

178. Zheng Y, de la Cruz CC, Sayles LC, et al (2013) A rare population of CD24(+)ITGB4(+)Notch(hi) cells drives tumor propagation in NSCLC and requires Notch3 for self-renewal. Cancer Cell 24:59-74. https://doi.org/10.1016/j.ccr.2013.05.021

179. Dang TP, Eichenberger S, Gonzalez A, et al (2003) Constitutive activation of Notch3 inhibits terminal epithelial differentiation in lungs of transgenic mice. Oncogene 22:1988-1997. https://doi.org/10.1038/sj.onc.1206230

180. Eliasz S, Liang S, Chen Y, et al (2010) Notch-1 stimulates survival of lung adenocarcinoma cells during hypoxia by activating the IGF-1R pathway. Oncogene 29:2488-2498. https://doi.org/10.1038/onc.2010.7

181. Haruki N, Kawaguchi KS, Eichenberger S, et al (2005) Dominant-negative Notch3 receptor inhibits mitogen-activated protein kinase pathway and the growth of human lung cancers. Cancer Res 65:3555-3561. https://doi.org/10.1158/0008-5472.CAN-043132

182. Allen TD, Rodriguez EM, Jones KD, Bishop JM (2011) Activated Notch1 induces lung adenomas in mice and cooperates with Myc in the generation of lung 
adenocarcinoma. Cancer Res 71:6010-6018. https://doi.org/10.1158/0008-5472.CAN11-0595

183. Maraver A, Fernández-Marcos PJ, Herranz D, et al (2012) Therapeutic effect of $\gamma$ secretase inhibition in KrasG12V-driven non-small cell lung carcinoma by derepression of DUSP1 and inhibition of ERK. Cancer Cell 22:222-234. https://doi.org/10.1016/j.ccr.2012.06.014

184. Yang Y, Ahn Y-H, Gibbons DL, et al (2011) The Notch ligand Jagged2 promotes lung adenocarcinoma metastasis through a miR-200-dependent pathway in mice. J Clin Invest 121:1373-1385. https://doi.org/10.1172/JCI42579

185. Hassan KA, Wang L, Korkaya H, et al (2013) Notch pathway activity identifies cells with cancer stem cell-like properties and correlates with worse survival in lung adenocarcinoma. Clin Cancer Res 19:1972-1980. https://doi.org/10.1158/10780432.CCR-12-0370

186. Agrawal N, Jiao Y, Bettegowda C, et al (2012) Comparative genomic analysis of esophageal adenocarcinoma and squamous cell carcinoma. Cancer Discov 2:899-905. https://doi.org/10.1158/2159-8290.CD-12-0189

187. Pickering CR, Zhang J, Yoo SY, et al (2013) Integrative genomic characterization of oral squamous cell carcinoma identifies frequent somatic drivers. Cancer Discov 3:770-781. https://doi.org/10.1158/2159-8290.CD-12-0537

188. Proweller A, Tu L, Lepore JJ, et al (2006) Impaired notch signaling promotes de novo squamous cell carcinoma formation. Cancer Res 66:7438-7444.

https://doi.org/10.1158/0008-5472.CAN-06-0793

189. Rothenberg SM, Ellisen LW (2012) The molecular pathogenesis of head and neck squamous cell carcinoma. J Clin Invest 122:1951-1957. https://doi.org/10.1172/jci59889

190. Aster JC, Blacklow SC (2012) Targeting the Notch pathway: twists and turns on the road to rational therapeutics. J Clin Oncol 30:2418-2420. https://doi.org/10.1200/JCO.2012.42.0992

191. Palomero T, Ferrando A (2009) Therapeutic targeting of NOTCH1 signaling in T-cell acute lymphoblastic leukemia. Clin Lymphoma Myeloma 9 Suppl 3:S205-210. https://doi.org/10.3816/CLM.2009.s.013

192. Real PJ, Tosello V, Palomero T, et al (2009) Gamma-secretase inhibitors reverse glucocorticoid resistance in T cell acute lymphoblastic leukemia. Nat Med 15:50-58. https://doi.org/10.1038/nm.1900

193. Zhou B-BS, Peyton M, He B, et al (2006) Targeting ADAM-mediated ligand cleavage to inhibit HER3 and EGFR pathways in non-small cell lung cancer. Cancer Cell 10:39-50. https://doi.org/10.1016/j.ccr.2006.05.024

194. Purow B (2012) Notch inhibition as a promising new approach to cancer therapy. Adv Exp Med Biol 727:305-319. https://doi.org/10.1007/978-1-4614-0899-4_23 
195. Wu Y, Cain-Hom C, Choy L, et al (2010) Therapeutic antibody targeting of individual Notch receptors. Nature 464:1052-1057. https://doi.org/10.1038/nature08878

196. Funahashi Y, Hernandez SL, Das I, et al (2008) A notch1 ectodomain construct inhibits endothelial notch signaling, tumor growth, and angiogenesis. Cancer Res 68:4727-4735. https://doi.org/10.1158/0008-5472.CAN-07-6499

197. Hicks C, Ladi E, Lindsell C, et al (2002) A secreted Delta1-Fc fusion protein functions both as an activator and inhibitor of Notch1 signaling. J Neurosci Res 68:655-667. https://doi.org/10.1002/jnr.10263

198. Moellering RE, Cornejo M, Davis TN, et al (2009) Direct inhibition of the NOTCH transcription factor complex. Nature 462:182-188. https://doi.org/10.1038/nature08543

199. Ilagan MXG, Kopan R (2013) Selective blockade of transport via SERCA inhibition: the answer for oncogenic forms of Notch? Cancer Cell 23:267-269. https://doi.org/10.1016/j.ccr.2013.02.020

200. Krämer A, Mentrup T, Kleizen B, et al (2013) Small molecules intercept Notch signaling and the early secretory pathway. Nat Chem Biol 9:731-738. https://doi.org/10.1038/nchembio.1356

201. Bray SJ (2016) Notch signalling in context. Nat Rev Mol Cell Biol 17:722-735. https://doi.org/10.1038/nrm.2016.94 
A

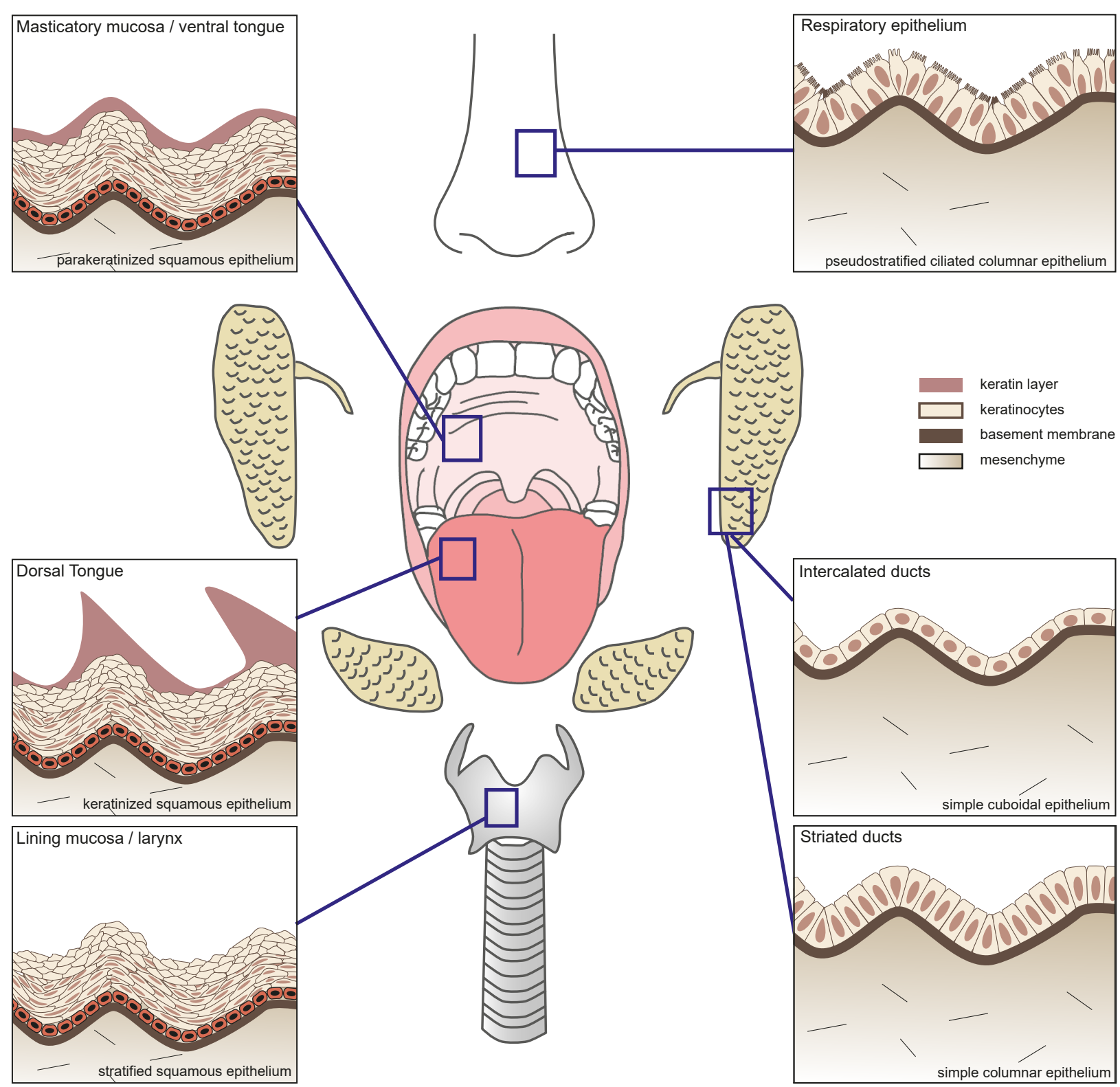


A

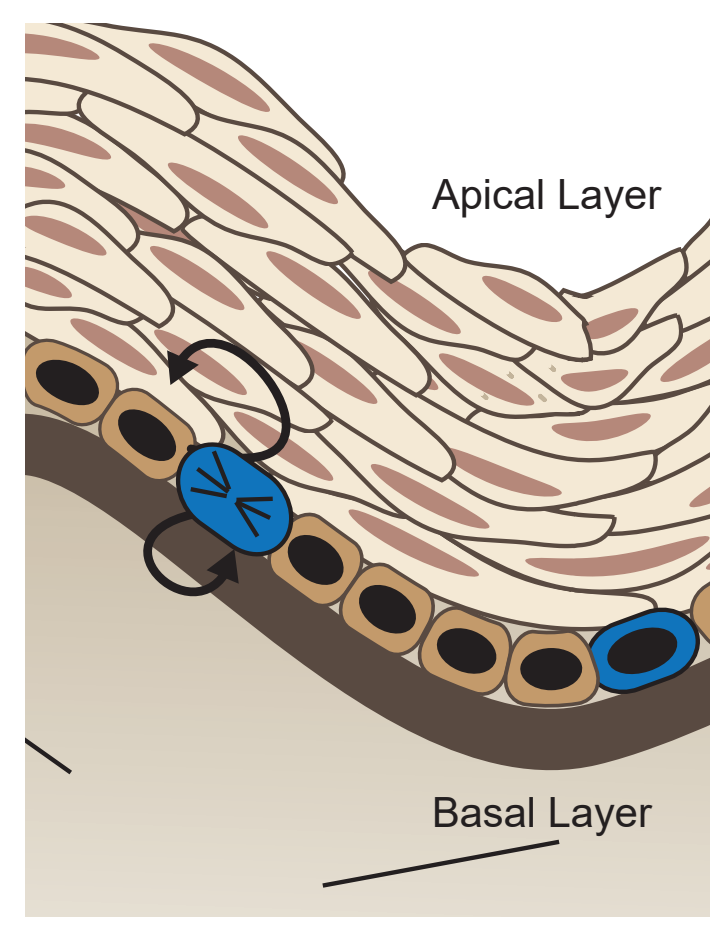

B

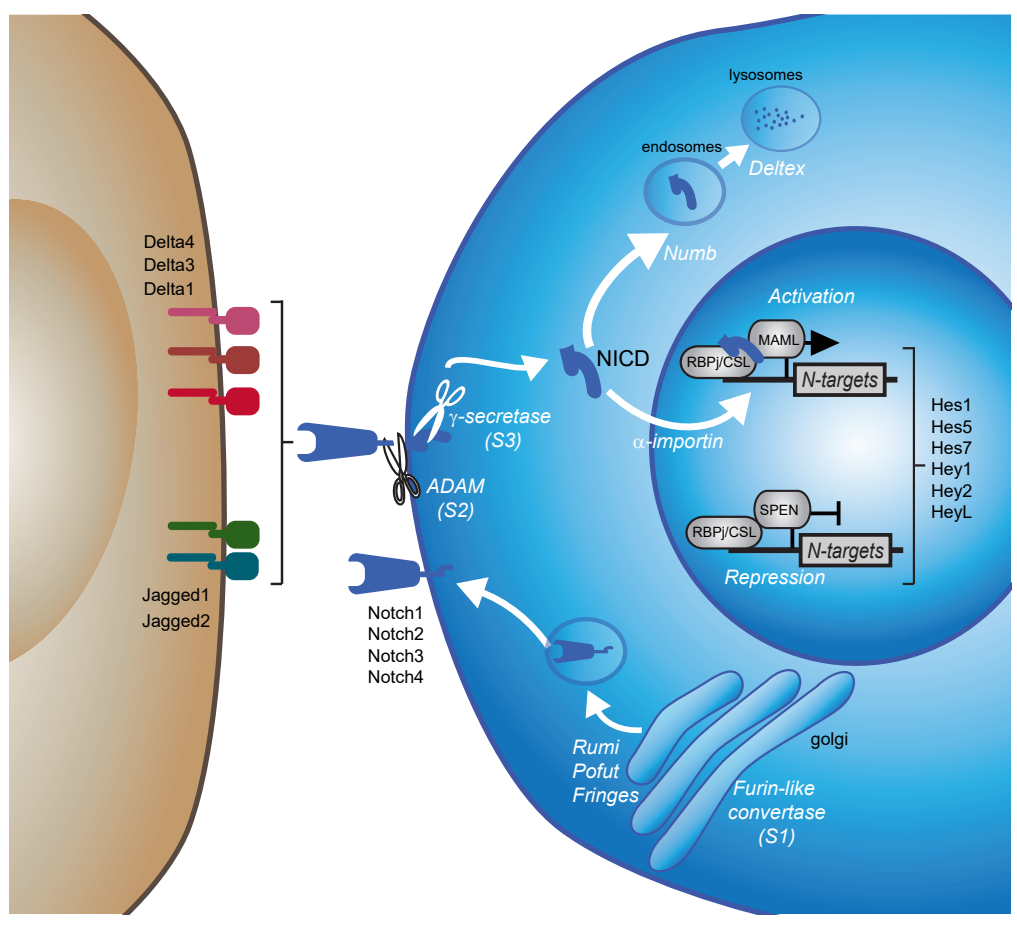




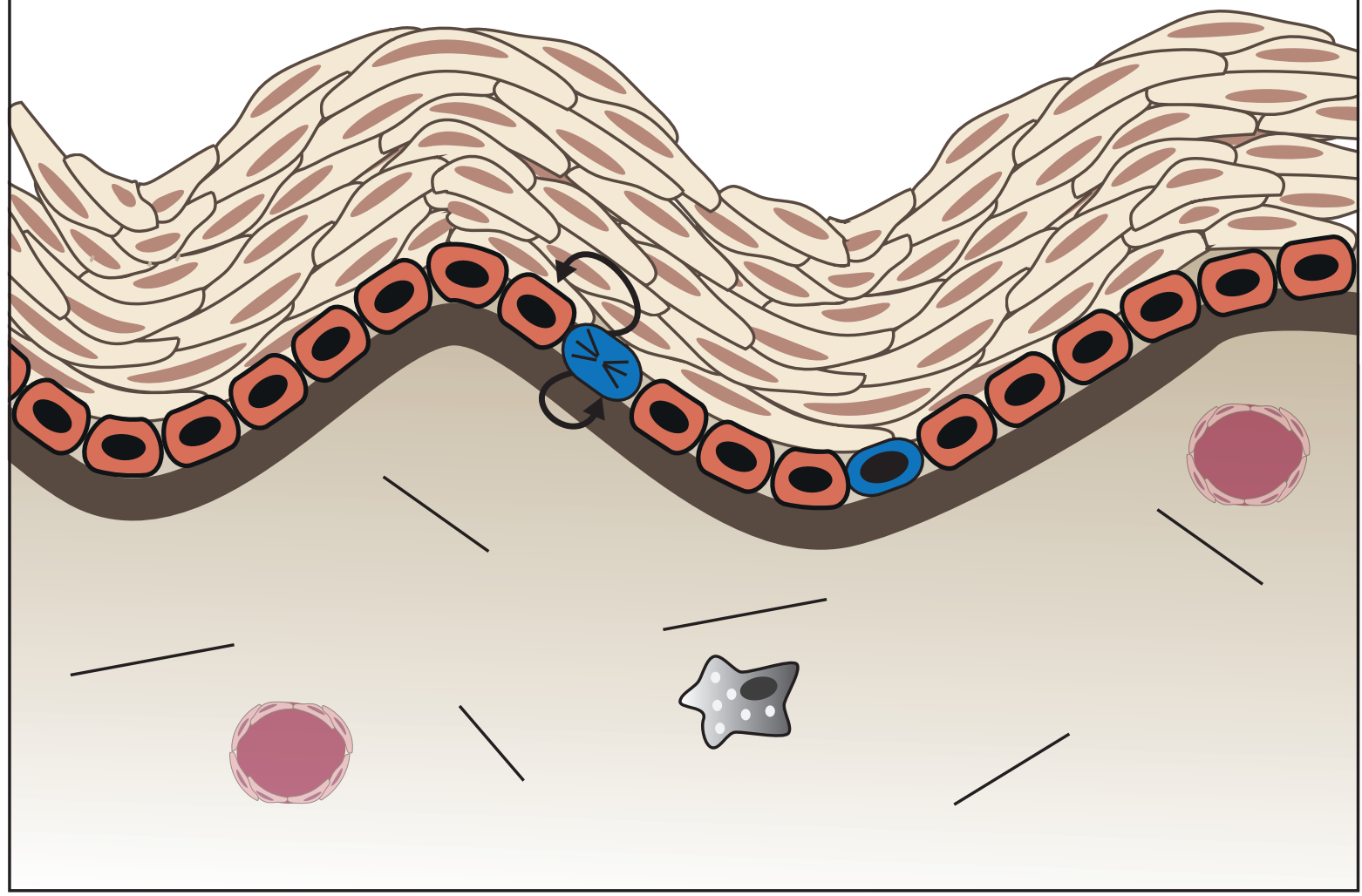

B

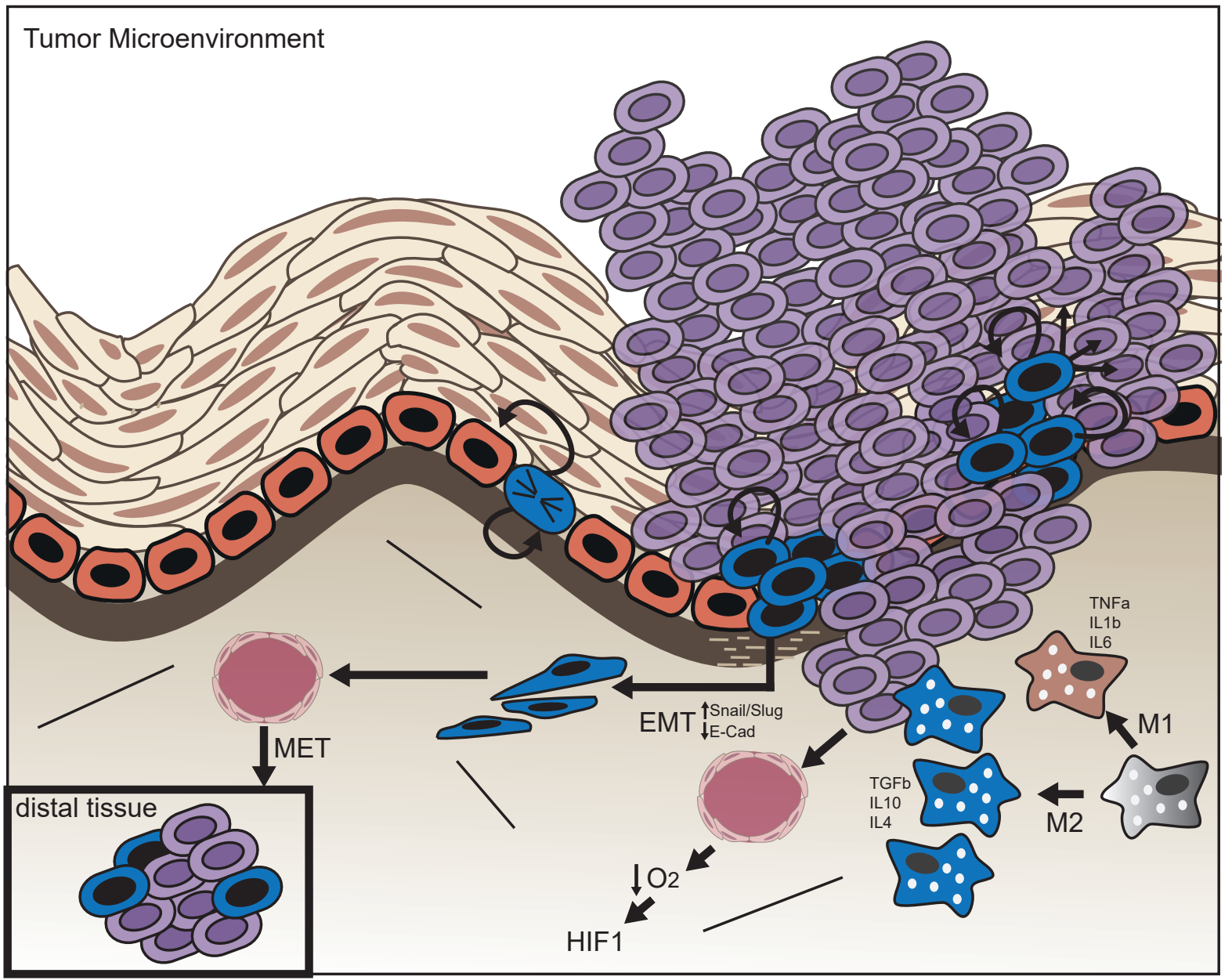

